\title{
An Experimental Study on the Slippage Effects of Sandstone under Confining Pressure and Low Pore Pressure Conditions
}

\author{
Zhengdai Li $\mathbb{D}^{1}{ }^{1}$ Jianping Zuo $\mathbb{D}^{1,2}$ Yue Shi, ${ }^{1}$ Fei Xu, ${ }^{1}$ Meilu Yu, ${ }^{1}$ and Changning Mi ${ }^{1}$ \\ ${ }^{1}$ School of Mechanics \& Civil Engineering, China University of Mining and Technology (Beijing), Beijing 100083, China \\ ${ }^{2}$ State Key Laboratory of Coal Resources and Safe Mining, China University of Mining and Technology (Beijing), \\ Beijing 100083, China
}

Correspondence should be addressed to Jianping Zuo; zjp@cumtb.edu.cn

Received 8 December 2019; Accepted 6 February 2020; Published 24 February 2020

Academic Editor: Jaewon Jang

Copyright (c) 2020 Zhengdai Li et al. This is an open access article distributed under the Creative Commons Attribution License, which permits unrestricted use, distribution, and reproduction in any medium, provided the original work is properly cited.

\begin{abstract}
Due to the influences of various factors, such as temperature, stress, and composition, the research regarding rock permeability has been complicated. This study examined the variation laws of sandstone specimens under changing rates of confining and pore pressures after high-temperature heat treatments. The results showed that the free water in the rock volatilized during the lowtemperature heat treatments in the range of $100^{\circ} \mathrm{C}$ to $300^{\circ} \mathrm{C}$, with the increase of the heat-treatment temperature above $500^{\circ} \mathrm{C}$; the crystal water in the rock is gradually separated out; and the particles in the samples had undergone phase transformations resulting in increased permeability. According to ultrasonic wave velocity test results, the internal cracks of the samples expanded with the increases in the heat-treatment temperatures. In addition, the high-temperature heat treatments were found to improve the accuracy of the direction of the Earth's stress when using circumferential wave velocity anisotropy methods. Under the influence of slippage effects, as the pore pressure increased, the measured permeability of the samples decreased and the slippage effect occurs in the rock samples with the permeability of $10^{-3} \mu \mathrm{m}^{2} \sim 10^{-6} \mu \mathrm{m}^{2}$. The experimental results showed that the contribution rate of the slippage effect decreases with the increase of the heat-treatment temperature of the specimen, and the contribution rates of the sandstone slippage effect were generally higher than $5 \%$. Therefore, the impact effects on the permeability of sandstone slippage should be considered in practical engineering processes.
\end{abstract}

\section{Introduction}

In recent years, the characteristics of rock permeability have become hot issues in rock physical and mechanical property research. Rock permeability problems exist in many fields, such as underground coal gasification, coalbed methane engineering, shale gas development, and underground reservoir constructions. According to the traditional theory, the absolute permeability of rock measured under different seepage media remains unchanged. However, due to many factors, such as temperature, stress states, and pore pressure changes, the permeability levels measured by the gas and the permeability levels measured by the liquid are often inconsistent. In addition, these differences become increasingly significant as the rock permeability decreases [1].

Many scholars have examined rock permeability characteristics under the influences of multiple factors. For temper- ature factors, Weinbrandt and Casse studied the changes in permeability of Bois sandstone at different temperature levels; also, the changes in the absolute permeability induced the mechanical stress caused by the expansion of rock particles [2]. The case study results had indicated that the influences of temperature on the permeability of cemented sandstone were related to the properties of saturated fluid [3]. Jianping et al. studied the thermal cracking behaviors of sandstone and Beishan granite at different temperature levels and then analyzed the influence mechanisms of hightemperature levels in the thermal cracking of rock, as well as the types of thermal cracking $[4,5]$. Lin [6] researched granite wherein the fluid inclusions burst under hightemperature conditions, causing a lot of new cracks inside the rock. For stress factors: Iftikhar and Malik studied the effect of stress on shale permeability and established a nonlinear transport model for single-phase gas flow in tight 


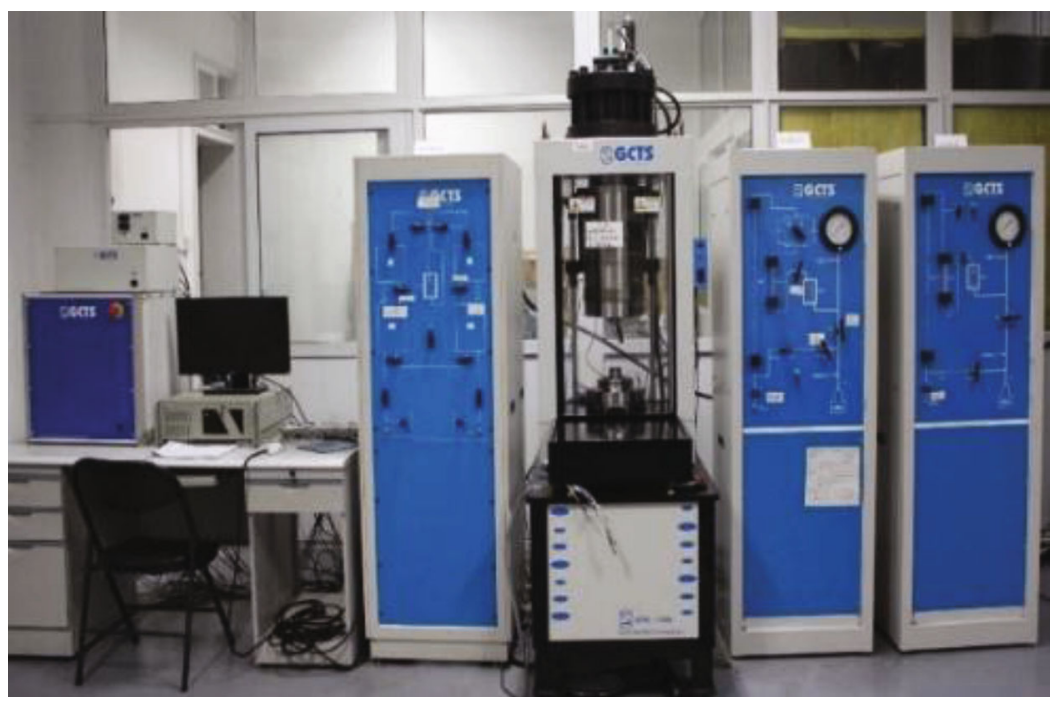

FIGURE 1: GCTS test system.

porous media [7]. Yang and Aplin [8, 9] conducted permeability experiments under the combined actions of confining pressure and pore pressure using more than 30 mudstone samples and found that the influences of the pore pressure levels on the permeability of the examined samples were greater than that of the confining pressure levels. According to Yang et al.'s research, the rock sample's fractures and pores are more stress-sensitive at low effective stress than at high effective stress. Stress has a great influence on the structural changes of rock pores and fractures $[10,11]$.

The research results presented by Chen et al. revealed that the process of the increasing pressure was more sensitive than that of the decreasing pressure [12]. The research by Chen et al. and Hong-xue et al. proved that the effective stress has a great influence on the permeability of shale $[13,14]$. In 1941, Klinkenberg attempted to explain the differences between gas-measured permeability and liquid-measured permeability under slippage effect conditions. Since then, many related research studies have been carried out regarding slippage effects [15-18]. In one such study, Ma et al. examined the transition processes of rock using Darcy's Law and slippage flow rates and successfully obtained the Knudsen number threshold for induced slippage effects [19]. Suleimanov et al. present an experimental study of gas condensate flow in porous media at pressures above the dew point pressure, and the mechanism of gas slip effect near the dew point pressure in condensate flow in porous media was analyzed [20].

In order to more clearly understand the change law of permeability characteristics of sandstone under complex conditions, this paper took multistage confining pressure and variable pore pressure experiments of sandstone after heat treatment on the background of underground coal gasification engineering. To make the experimental results more compatible with the underground coal gasification project, the rock sample were selected from the Ehebaolige coalfield in Inner Mongolia, a demonstration base for underground coal gasification in China. Through experiments, the variation

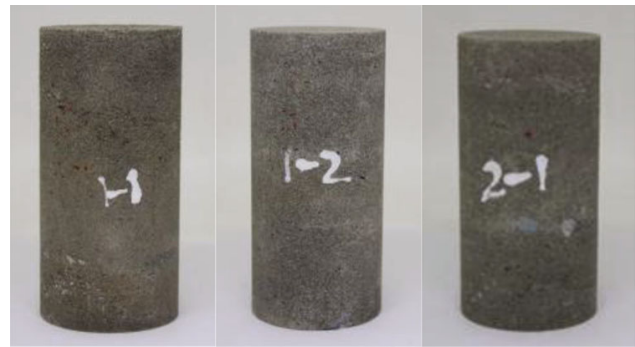

FIgURE 2: Sandstone specimens.

of the permeability of sandstone after high-temperature heating with confining pressure and pore pressure was obtained. Combining the slippage effect, the permeability test results were modified. The research results provide some theoretical guidance for seepage issues which may be encountered during future practical engineering projects.

\section{The Experimental Processes to Study Permeability of Sandstone}

2.1. Experimental Equipment and Materials. This study's experimental testing process adopted a RTR-2000 servo test system (Figure 1) produced by GCTS. The system is able to perform conventional single and triaxial experiments, along with Brazilian splitting tests, permeability tests, and wave speed tests.

The rock samples examined in this study were obtained from coal seam roof sandstone in the gasification and combustion area of the Ehebaolige coalfield, Inner Mongolia Autonomous Region. The rock was processed into $50 * 100 \mathrm{~mm}$ test specimens. From all processed test specimens, three test specimens with good appearance, close weight, and close porosity were selected for experiments (Figure 2). The basic physical properties of rocks are shown in Table 1. 
TABLE 1: Basic physical parameters of sandstone.

\begin{tabular}{lccc}
\hline & Density $\left(\mathrm{kg} / \mathrm{m}^{3}\right)$ & Porosity (\%) & Weight $(\mathrm{g})$ \\
\hline Sample 1-1 & 2.1874 & 14.196 & 420.45 \\
Sample 1-2 & 2.1885 & 12.835 & 413.59 \\
Sample 2-1 & 2.1694 & 15.013 & 414.56 \\
\hline
\end{tabular}

TABLE 2: Rock sample permeability test points.

\begin{tabular}{lccc}
\hline $\begin{array}{l}\text { Confining } \\
\text { pressure } \\
(\mathrm{MPa})\end{array}$ & $\begin{array}{c}\text { Inlet pore } \\
\text { pressure } \\
(\mathrm{MPa})\end{array}$ & $\begin{array}{c}\text { Outlet pore } \\
\text { pressure } \\
(\mathrm{MPa})\end{array}$ & $\begin{array}{c}\text { Heat-treatment } \\
\text { temperature }\left({ }^{\circ} \mathrm{C}\right)\end{array}$ \\
\hline & 0.7 & 0.3 & \\
$5,10,15,20$, & 0.6 & 0.2 & $100,300,500,700$ \\
25,30 & 0.5 & 0.1 & \\
& 0.4 & 0 & \\
\hline
\end{tabular}

The permeability tests conducted in this study adopted a pulse decay method, with the gas permeation pressure levels of the test machine reaching a maximum of $1 \mathrm{MPa}$. During the testing process, a pressure difference could be formed between the upper and lower ends of the rock specimen by releasing the pressure of the bottom ram. The rock permeability levels were calculated using the pressure differences and time curves. In addition, circumferential velocity anisotropy experiments were completed using an ultrasonic testing system. The sandstone specimens with different heat-treatment temperatures were tested for circumferential wave velocity. The evolution of the pores and cracks in the rock samples were predicted by the changes in the wave velocity.

2.2. Experimental Program. During this study's permeability tests, first, the rock was heated to $100^{\circ} \mathrm{C}$ for three hours and then taken out. Subsequently, the rock was initially fixed with $0.5 \mathrm{MPa}$ of axial pressure and $2 \mathrm{MPa}$ of surrounding rock, and gas saturation was simultaneously performed. After the gas was saturated, confining pressures of $5 \mathrm{MPa}$, $10 \mathrm{MPa}, 15 \mathrm{MPa}, 20 \mathrm{MPa}, 25 \mathrm{MPa}$, and $30 \mathrm{MPa}$ were applied to the samples, and the pore pressure at each stage of confining pressure was set to $0.2 \mathrm{MPa}, 0.3 \mathrm{MPa}, 0.4 \mathrm{MPa}$, and $0.5 \mathrm{MPa}$. After the permeability test was completed at a confining pressure of $30 \mathrm{MPa}$, the test sample should be taken out, and the same rock sample was heated to the next-stage heat-treatment temperature $\left(300^{\circ} \mathrm{C} / 500^{\circ} \mathrm{C} / 700^{\circ} \mathrm{C}\right)$, and then the above-mentioned cycle step experiment was performed. The confining pressure and pore pressure of each test point are shown in Table 2. The permeability test device is shown in Figure 3.

The test results of the three test pieces have similar trends and similar results, so in order to reduce the amount of calculation and article length, the average of the experimental results of the three samples is used, and then the average value of the experimental results is used to continue the indepth analysis.

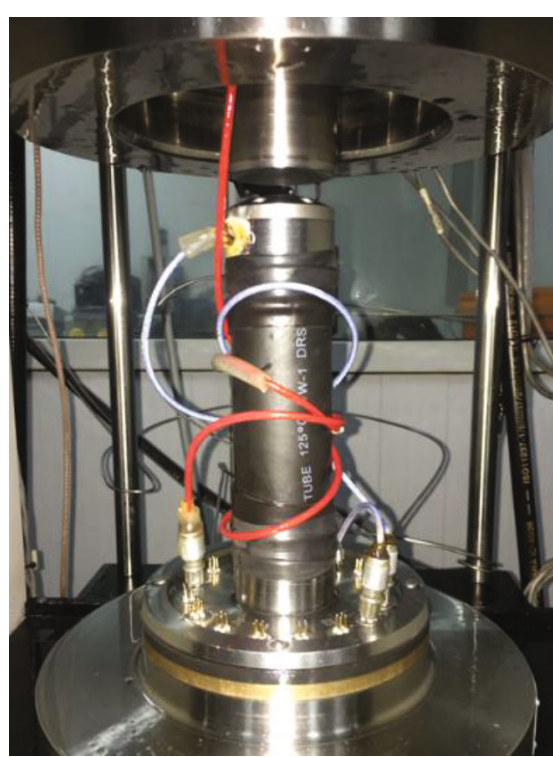

Figure 3: Permeability experimental device.

\section{Permeability Variations of the Sandstone Samples under Different Confining Pressures, Pore Pressures, and Heat- Treatment Temperatures}

\subsection{Analysis of Permeability Test Results under Confining} Pressure and Pore Pressure Conditions. Figure 4 details the permeability curves of the sandstone samples under different confining pressure conditions. The pore pressure levels controlled by the testing process were $0.2 \mathrm{MPa}, 0.3 \mathrm{MPa}$, $0.4 \mathrm{MPa}$, and $0.5 \mathrm{MPa}$. Figures $4(\mathrm{a})-4$ (d) show the measured results at the heat-treatment temperatures of $100^{\circ} \mathrm{C}, 300^{\circ} \mathrm{C}$, $500^{\circ} \mathrm{C}$, and $700^{\circ} \mathrm{C}$, respectively.

As can be seen in Figure 4. In this study, the permeability of the rock samples had gradually decreased with the continuous increases in the confining pressure levels, and the permeability and confining pressure are approximately linear. According to Yang et al.'s research $[10,11]$, the rock sample's fractures and pores are more stress-sensitive at low effective stress than at high effective stress. Therefore, in this experiment, as the confining pressure increases, the pores and cracks inside the sandstone samples were compacted, and the seepage channels had been gradually compressed, so the permeability gradually decreased as the confining pressure increased.

It was observed in this study that with the increases in the heat-treatment temperatures, the permeability levels of the sandstone samples had also increased under the same confining pressure. This shows that before the heat-treatment temperature was raised to $300^{\circ} \mathrm{C}$, the free water inside the rock was volatilized. When the heat-treatment temperature had increased to above $500^{\circ} \mathrm{C}$, the combined water inside the rock volatilizes, causing the pores to increase, and the stress generated by the particle expansion causes the cracks to continue to develop, resulting in a continuous increase in rock permeability [2]. Lin [6] studied the granite and found that the fluid 


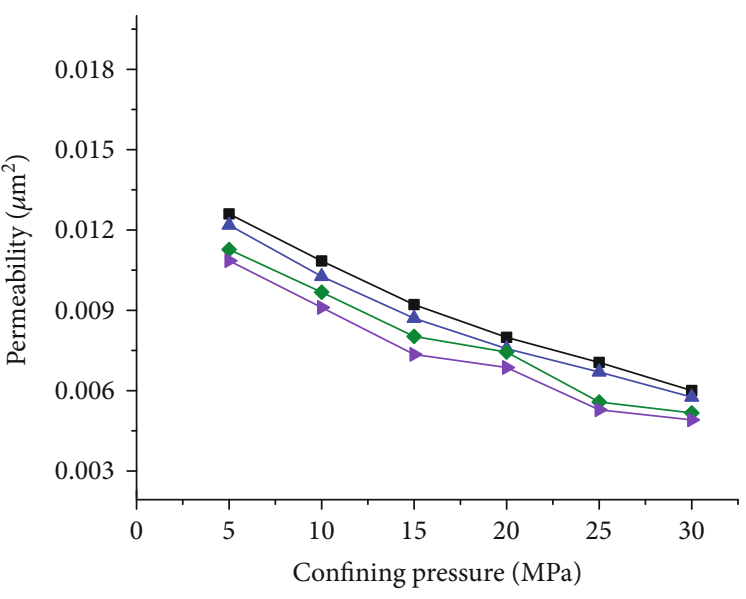

$100^{\circ} \mathrm{C}$ heat-treated

pore pressure

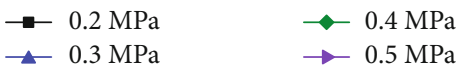

(a) $100^{\circ} \mathrm{C}$ heat-treated test piece

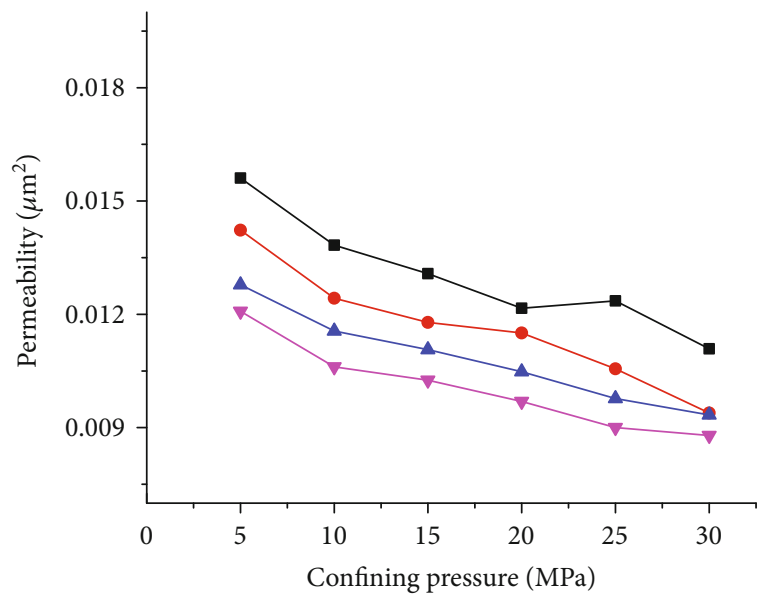

$500^{\circ} \mathrm{C}$ heat-treated

pore pressure

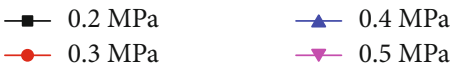

(c) $500^{\circ} \mathrm{C}$ heat-treated test piece

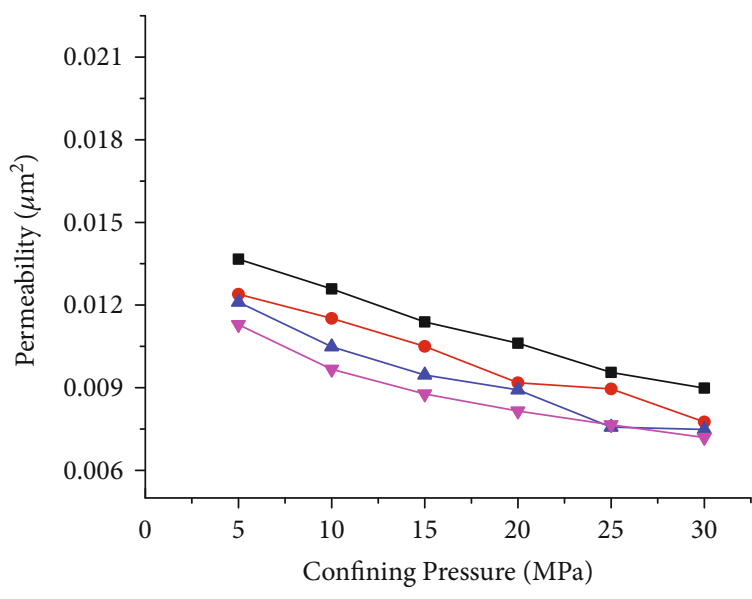

$300^{\circ} \mathrm{C}$ heat-treated

pore pressure

$\rightarrow 0.2 \mathrm{MPa} \quad \longrightarrow 0.4 \mathrm{MPa}$

$\rightarrow 0.3 \mathrm{MPa} \quad \rightarrow 0.5 \mathrm{MPa}$

(b) $300^{\circ} \mathrm{C}$ heat-treated test piece

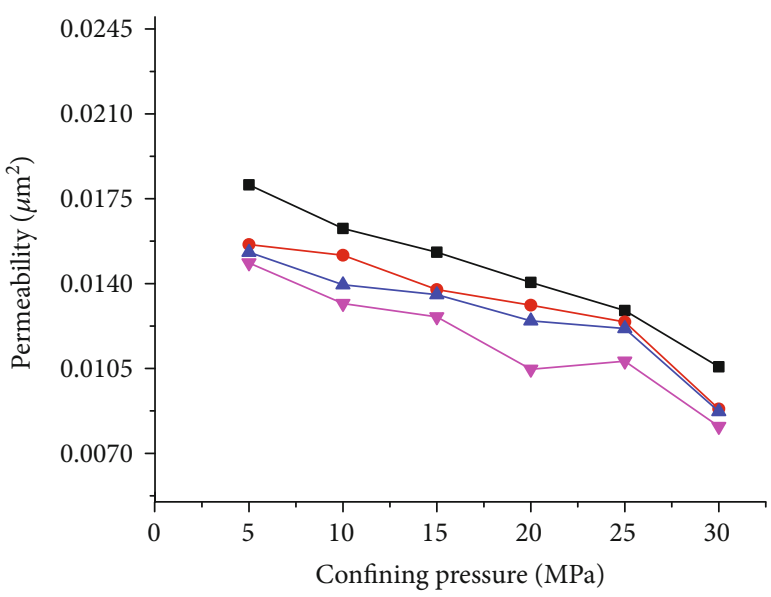

$700^{\circ} \mathrm{C}$ heat-treated

pore pressure

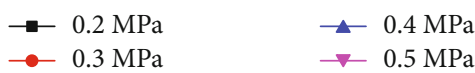

(d) $700^{\circ} \mathrm{C}$ heat-treated test piece

Figure 4: Permeability changes under the different confining pressure levels.

inclusions existing in the rock were broken under high temperature, which caused new microcracks in the rock. However, because sandstone is a granular rock, there may be no fluid inclusions in the sandstone. Therefore, it is believed that the permeability of the sandstone specimens after hightemperature heat treatment is not affected by the fluid inclusions. The structural changes of sandstone subjected to high temperature need to be further studied.

Figure 5 illustrates the change curves of the permeability at four heat-treatment temperatures under different pore pressure conditions. It can be seen in the figure that, with the increases in pore pressure, the permeability levels of the sandstone specimens had gradually decreased. The gas pressure level of the tests was less than $1 \mathrm{MPa}$, which was considered to represent a low pore pressure stage. Therefore, it was assumed that slippage effects may have occurred during the experiment. Since changes in pore pressure will change the free paths of molecules, when the average free path of the molecules is close to the pore radius of the sandstone, the collision between gas molecules and pore walls will produce a slippage flow. This slippage flow will then result in the gas permeability changing from a viscous flow to a slippage flow. Therefore, changes in the gas permeability under the influence of slippage effects may potentially occur under low pore pressure conditions. The specific definition and mechanism of slippage effect will be discussed in detail in Section 5 .

3.2. Analysis of the Confining Pressure Change Rates and Permeability Sensitivity Coefficients. In order to study the effects of confining pressure on the rock samples' 

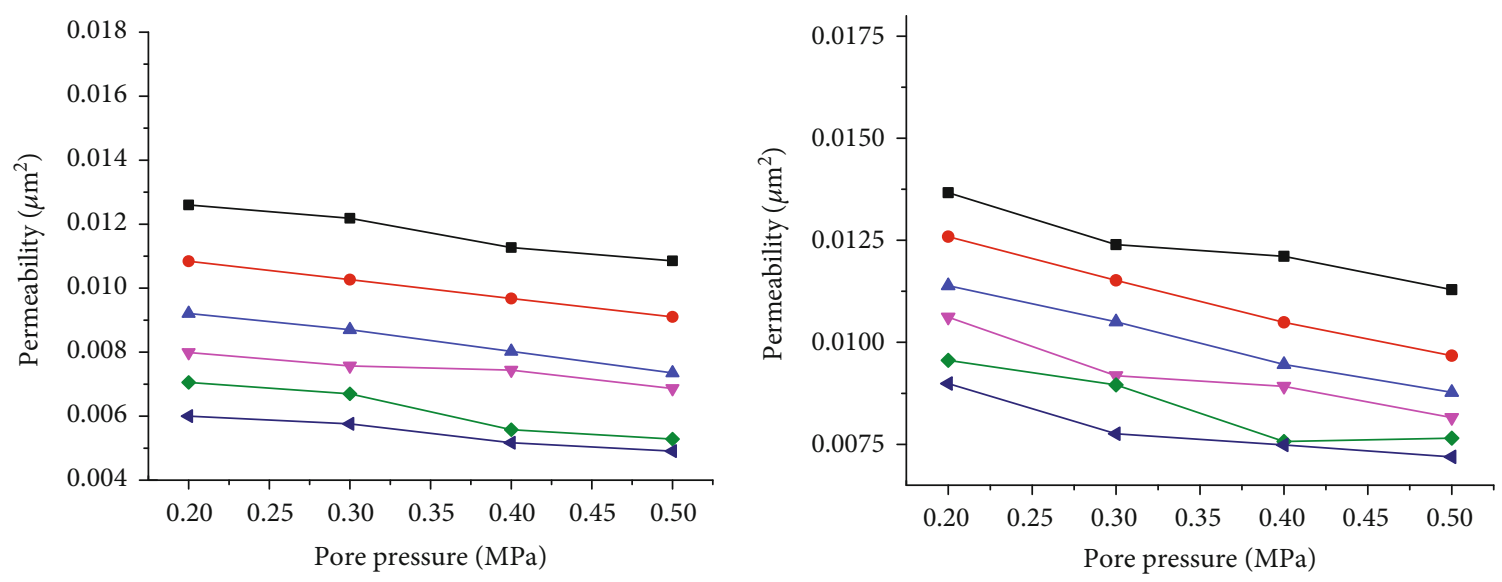

$100^{\circ} \mathrm{C}$ heat-treated confining pressure

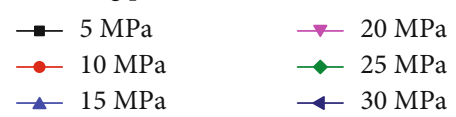

(a) $100^{\circ} \mathrm{C}$ heat-treated test piece

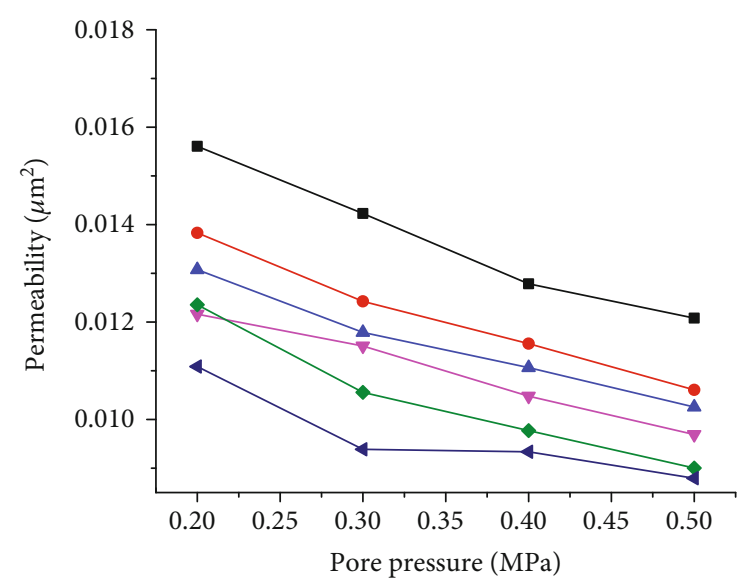

$500^{\circ} \mathrm{C}$ heat-treated confining pressure

$\begin{array}{ll}\rightarrow 5 \mathrm{MPa} & \rightarrow 20 \mathrm{MPa} \\ \rightarrow 10 \mathrm{MPa} & \multimap-25 \mathrm{MPa} \\ \leftarrow 15 \mathrm{MPa} & \multimap 30 \mathrm{MPa}\end{array}$

(c) $500^{\circ} \mathrm{C}$ heat-treated test piece $300^{\circ} \mathrm{C}$ heat-treated confining pressure

$$
\begin{array}{ll}
\rightarrow 5 \mathrm{MPa} & \rightarrow 20 \mathrm{MPa} \\
\rightarrow-10 \mathrm{MPa} & \rightarrow-\leftarrow 25 \mathrm{MPa} \\
\longleftarrow 15 \mathrm{MPa} & \longrightarrow 50 \mathrm{MPa}
\end{array}
$$

(b) $300^{\circ} \mathrm{C}$ heat-treated test piece

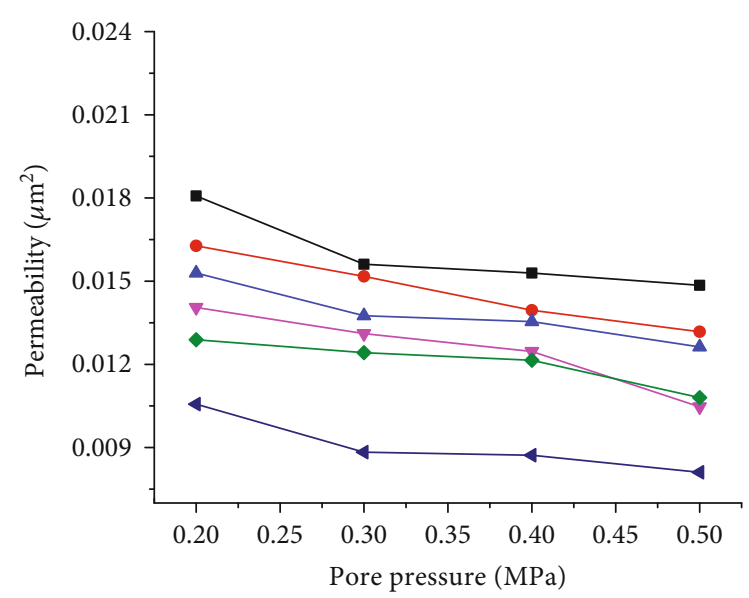

$700^{\circ} \mathrm{C}$ heat-treated confining pressure

$\begin{array}{ll}\rightarrow 5 \mathrm{MPa} & \rightarrow 20 \mathrm{MPa} \\ \rightarrow 10 \mathrm{MPa} & \multimap-25 \mathrm{MPa} \\ \leftarrow 15 \mathrm{MPa} & \leftarrow 30 \mathrm{MPa}\end{array}$

(d) $700^{\circ} \mathrm{C}$ heat-treated test piece

Figure 5: Permeability changes under the different pore pressure levels.

permeability, the permeability change rates and permeability sensitivity coefficients were analyzed in this study. Subsequently, the permeability change rate curves (Figure 6) and permeability sensitivity coefficients (Figure 7) were obtained. During the test of this study, the pore pressure and confining pressure test values are gradually increased. For example, in this experiment, the confining pressure is first controlled to $5 \mathrm{MPa}$, and then the average pore pressure inside the sample is set to $0.2 \mathrm{MPa}, 0.3 \mathrm{MPa}, 0.4 \mathrm{MPa}$, and $0.5 \mathrm{MPa}$ for permeability testing. Subsequently, the confining pressure was increased to the preset confining pressure at the next level, and the pore pressure was set to $0.2 \mathrm{MPa}, 0.3 \mathrm{MPa}, 0.4 \mathrm{MPa}$, and $0.5 \mathrm{MPa}$ for testing again. In order to obtain the permeability change rate value, a defined one reference value is required first. According to the methods commonly used in other studies [21], the first value measured in experiments is generally used as the reference value. The first value experimentally measured in this paper is measured at a confining pressure of $5 \mathrm{MPa}$ and a pore pressure of $0.2 \mathrm{MPa}$. Therefore, the permeability test value of confining pressure of $5 \mathrm{MPa}$ and pore pressure of $0.2 \mathrm{MPa}$ is defined as the reference value. The formula used for calculating the permeability change rate was as follows [21]:

$$
\Delta k=\frac{k_{0}-k_{i}}{k_{0}} \times 100 \%,
$$



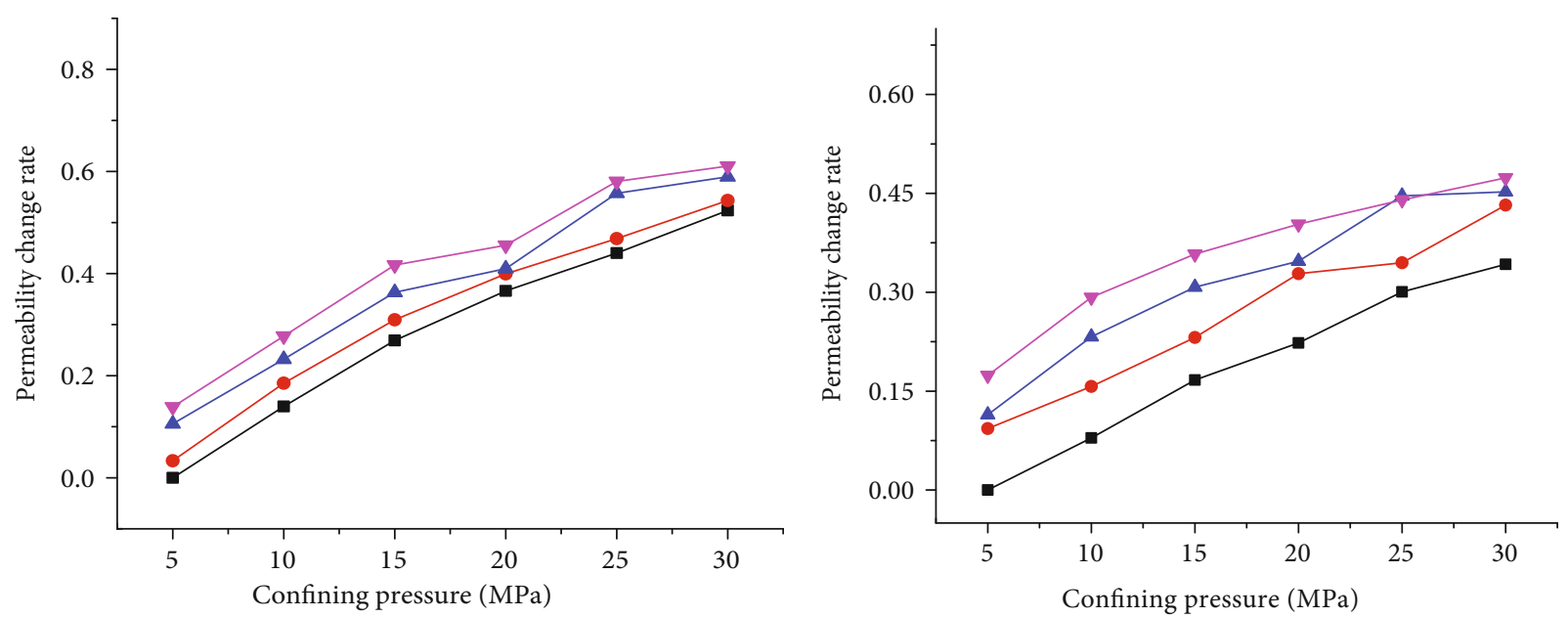

$100^{\circ} \mathrm{C}$ heat-treated pore pressure

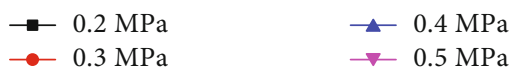

(a) $100^{\circ} \mathrm{C}$ heat-treated test piece

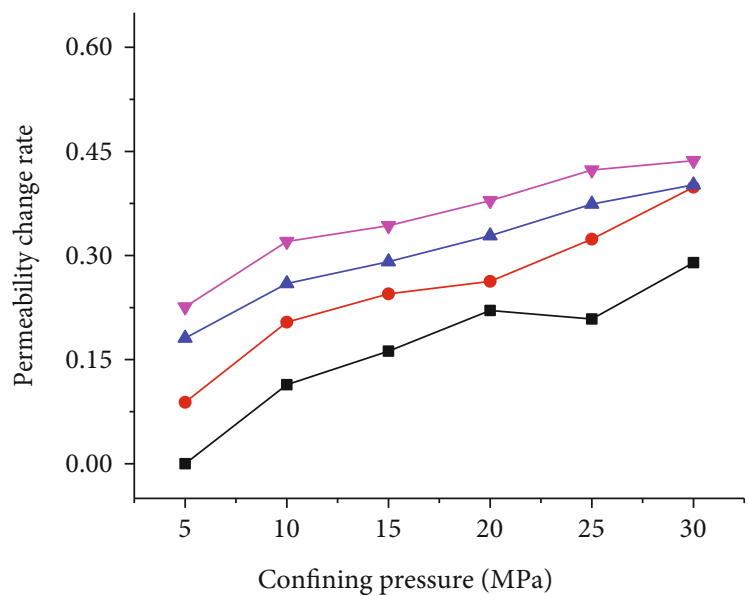

$500^{\circ} \mathrm{C}$ heat-treated pore pressure

$$
\begin{aligned}
& \rightarrow 0.2 \mathrm{MPa} \longrightarrow 0.4 \mathrm{MPa} \\
& \rightarrow 0.3 \mathrm{MPa} \longrightarrow 0.5 \mathrm{MPa}
\end{aligned}
$$

(c) $500^{\circ} \mathrm{C}$ heat-treated test piece $300^{\circ} \mathrm{C}$ heat-treated

pore pressure

$\begin{array}{ll}\rightarrow-0.2 \mathrm{MPa} & \rightarrow 0.4 \mathrm{MPa} \\ \rightarrow-0.3 \mathrm{MPa} & \rightarrow 0.5 \mathrm{MPa}\end{array}$

(b) $300^{\circ} \mathrm{C}$ heat-treated test piece

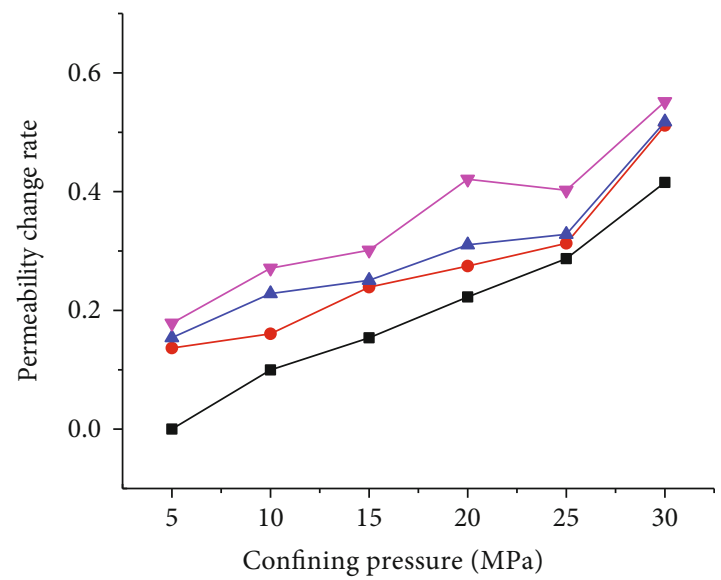

$700^{\circ} \mathrm{C}$ heat-treated pore pressure$$
\begin{array}{ll}
\rightarrow 0.2 \mathrm{MPa} & \rightarrow 0.4 \mathrm{MPa} \\
\rightarrow 0.3 \mathrm{MPa} & \rightarrow 0.5 \mathrm{MPa}
\end{array}
$$

(d) $700^{\circ} \mathrm{C}$ heat-treated test piece

FIGURE 6: Permeability change rate curves under the different confining pressure conditions.

where $k_{0}$ represents the reference permeability of the rock and $k_{i}$ is the permeability of the sandstone samples at other measuring points during the testing process.

The permeability sensitivity coefficient was defined as follows [21]:

$$
C_{C}=\frac{\Delta k_{i}-\Delta k_{0}}{P_{i}-P_{0}}
$$

where $p_{0}$ is the confining pressure $5 \mathrm{MPa}, p_{i}$ denotes the confining pressure of the other test points, and $\Delta k_{i}$ indicates the permeability change rate under the same pore pressure and different confining pressure conditions.
As shown in Figure 6, with the increases in the confining pressure levels, the permeability change rates of the sandstone samples gradually increased. The increased confining pressure led to the closures in the internal cracks in the sandstone samples and decreased pore spaces. Subsequently, the seepage channels of the sandstone samples became narrower and the permeability levels gradually decreased. By comparing the permeability change rates at different heattreatment temperatures, it was found that the permeability change rates were higher when the confining pressure was below $10 \mathrm{MPa}$. However, when the confining pressure was greater than $10 \mathrm{MPa}$, the permeability rates of the change curves slowed down and the permeability levels gradually decreased. These findings indicated that, after the confining 

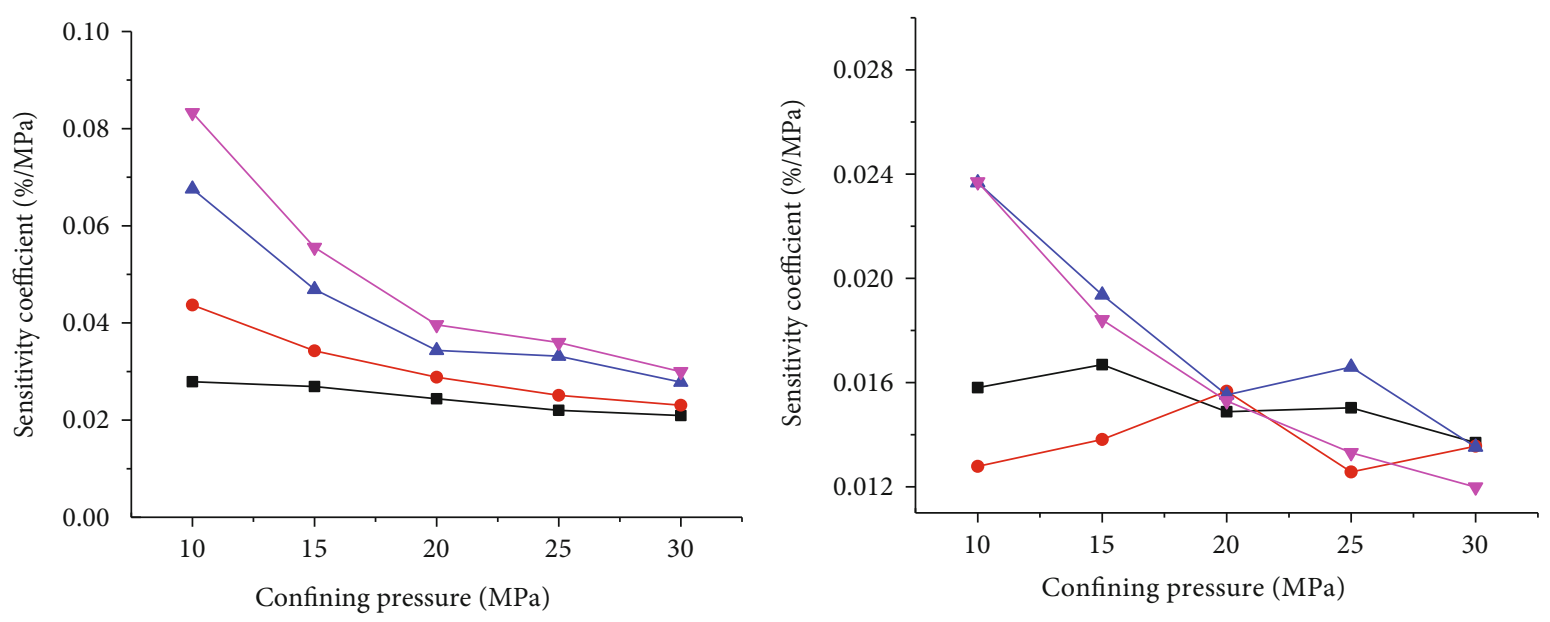

$100^{\circ} \mathrm{C}$ heat-treated pore pressure

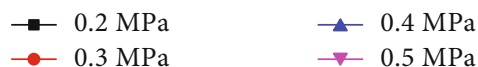

(a) $100^{\circ} \mathrm{C}$ heat-treated test piece

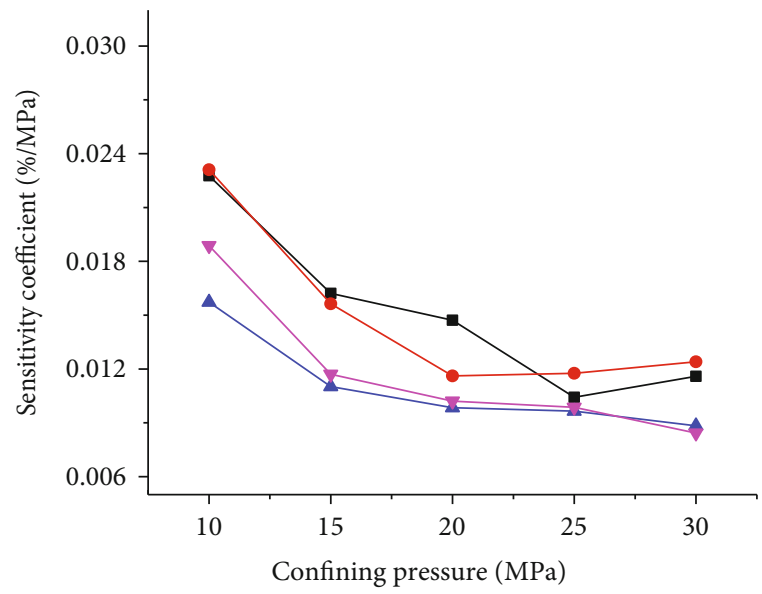

$500^{\circ} \mathrm{C}$ heat-treated pore pressure

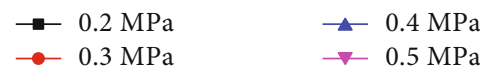

(c) $500^{\circ} \mathrm{C}$ heat-treated test piece $300^{\circ} \mathrm{C}$ heat-treated pore pressure

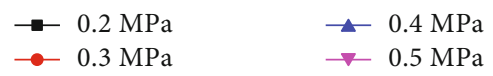

(b) $300^{\circ} \mathrm{C}$ heat-treated test piece

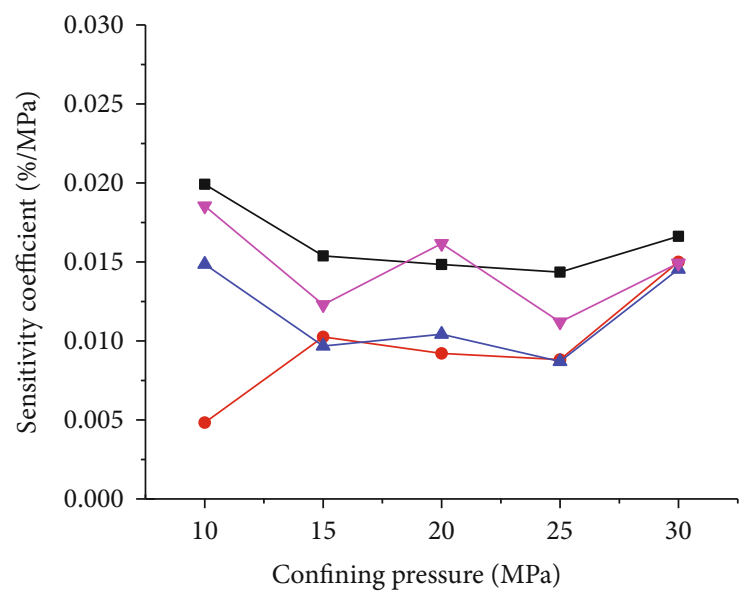

$700^{\circ} \mathrm{C}$ heat-treated pore pressure

$$
\begin{array}{ll}
\rightarrow 0.2 \mathrm{MPa} & \rightarrow 0.4 \mathrm{MPa} \\
\rightarrow 0.3 \mathrm{MPa} & \rightarrow 0.5 \mathrm{MPa}
\end{array}
$$

(d) $700^{\circ} \mathrm{C}$ heat-treated test piece

FIGURE 7: Confining pressure permeability sensitivity coefficient curves.

pressure became greater than $10 \mathrm{MPa}$, the decreased pore spaces of the sandstone samples under compression conditions had formed relatively dense skeletal structures.

Figure 7 illustrates a plot of the permeability sensitivity coefficient of a sandstone sample. It can be seen in the figure that with the increases in the confining pressure, the sensitivity coefficient of the rock confining pressure displayed a gradually decreasing trend. The specimens which were heat-treated at $300^{\circ} \mathrm{C}$ and $700^{\circ} \mathrm{C}$ displayed slight fluctuations. However, the overall trend remained gradually decreasing. These results indicated that with the increases in the confining pressure levels, the influences of the confining pressure on the changes in permeability had gradu- ally weakened. It has been observed in actual engineering processes that the greater the buried depth of the rock is, the less likely the rock permeability will be affected by the buried depth.

\subsection{Pore Permeability Change Rates and Permeability} Sensitivity Coefficients. The pore pressure permeability change rates and the pore pressure permeability sensitivity coefficient curves were obtained in this study using the same method, as detailed in Figures 8 and 9. During the calculations of the permeability change rates, the permeability change rate of the pore pressure level measured under the conditions of a confining pressure of $5 \mathrm{MPa}$ and a pore 

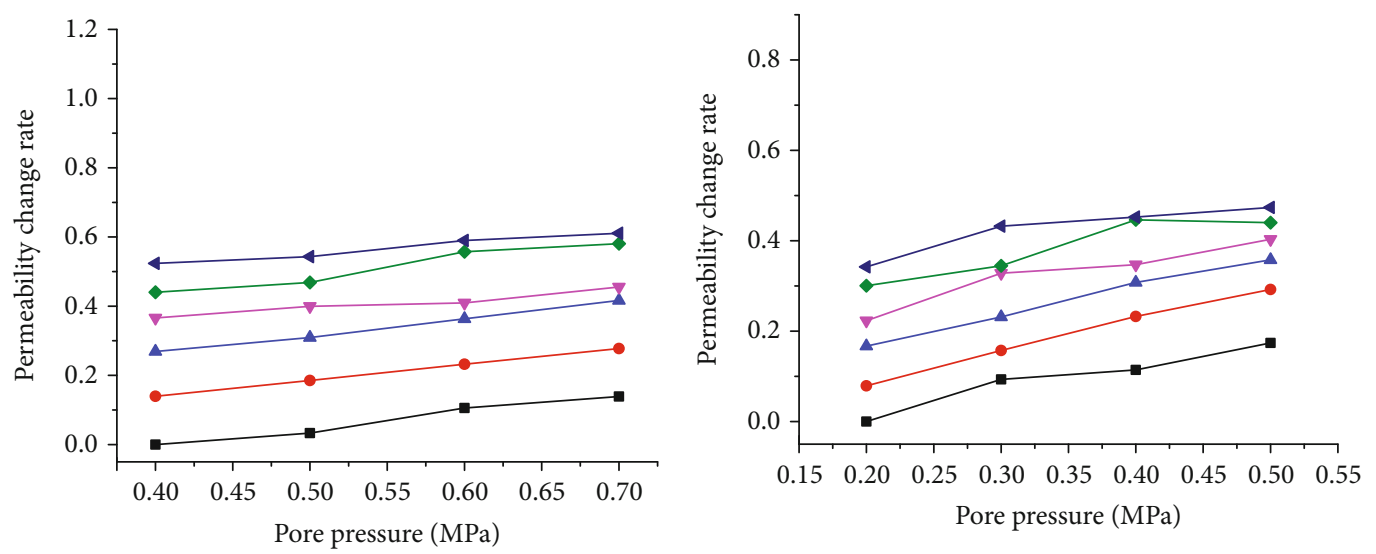

$100^{\circ} \mathrm{C}$ heat-treated

Confining pressure

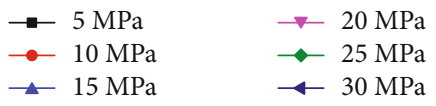

(a) $100^{\circ} \mathrm{C}$ heat-treated test piece

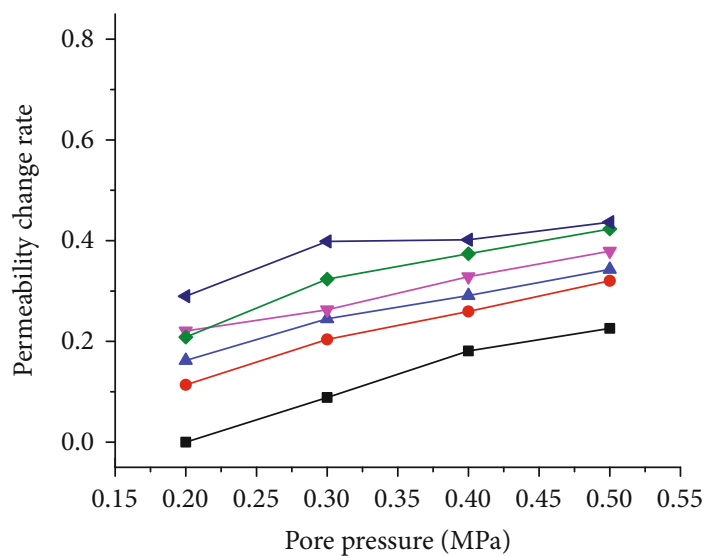

$500^{\circ} \mathrm{C}$ heat-treated

Confining pressure

$$
\begin{array}{ll}
\rightarrow-5 \mathrm{MPa} & \rightarrow 20 \mathrm{MPa} \\
\rightarrow-10 \mathrm{MPa} & -\leftarrow 25 \mathrm{MPa} \\
\rightarrow-15 \mathrm{MPa} & -530 \mathrm{MPa}
\end{array}
$$

(c) $500^{\circ} \mathrm{C}$ heat-treated test piece $300^{\circ} \mathrm{C}$ heat-treated

Confining pressure

$$
\begin{array}{ll}
\rightarrow-5 \mathrm{MPa} & \rightarrow 20 \mathrm{MPa} \\
\rightarrow 10 \mathrm{MPa} & \multimap 25 \mathrm{MPa} \\
\leftarrow 15 \mathrm{MPa} & -30 \mathrm{MPa}
\end{array}
$$

(b) $300^{\circ} \mathrm{C}$ heat-treated test piece

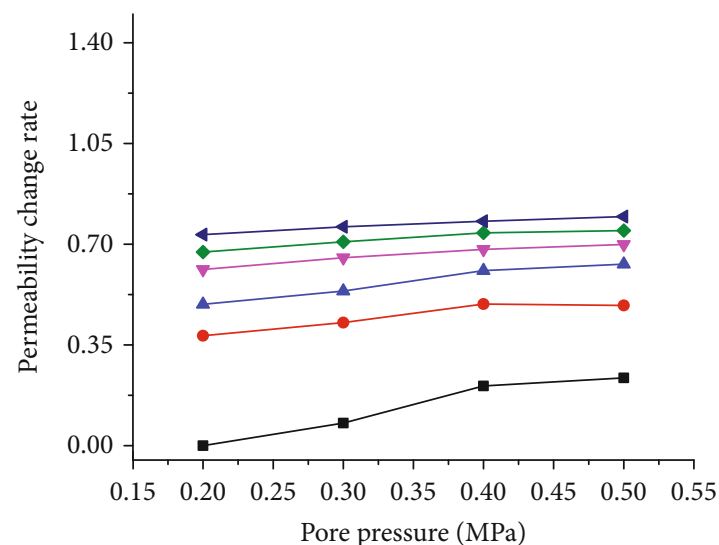

$700^{\circ} \mathrm{C}$ heat-treated

Confining pressure

$$
\begin{array}{ll}
\rightarrow 5 \mathrm{MPa} & \rightarrow-20 \mathrm{MPa} \\
\rightarrow 10 \mathrm{MPa} & \rightarrow 25 \mathrm{MPa} \\
\simeq 15 \mathrm{MPa} & \leftarrow 30 \mathrm{MPa}
\end{array}
$$

(d) $700^{\circ} \mathrm{C}$ heat-treated test piece

FIGURE 8: Permeability change rate curves under various pore pressure conditions.

pressure of $0.2 \mathrm{MPa}$ was defined as the reference value. The reference value selection principle is consistent with Formula (1) [21].

$$
\Delta k_{p}=\frac{k_{p 0}-k_{p i}}{k_{p 0}} \times 100 \%,
$$

where $k_{p 0}$ represents the rock reference permeability and $k_{p i}$ is the permeability of the sandstone samples at other experimental points during the testing process.

Therefore, the permeability sensitivity coefficient of pore pressure could be defined as follows [21]:

$$
C_{p}=\frac{\Delta k_{p i}-\Delta k_{p 0}}{p_{p i}-p_{p 0}} \times 100 \% \text {, }
$$

where $p_{p 0}$ indicates the pore pressure $0.5 \mathrm{MPa}, p_{p i}$ represents the pore pressure values of the other test points, and $\Delta k_{p i}$ is the permeability change rate under the same confining pressure and different pore pressure levels.

Figure 8 shows that with the increases in pore pressure, the permeability change rates of sandstone samples had gradually increased. The change in pore pressure increases the mean free path of the gas molecules, and the ratio of the mean free path to the pore radius changes, resulting in an increasing rate of change in permeability.

Figure 9 shows the pore pressure sensitivity coefficient curves of the sandstone samples. The sensitivity coefficients of the pore pressure were found to display no obvious upward or downward trends, which indicated that the influences of the pore pressure on the permeability levels of the sandstone specimens were not stable. It was determined that 


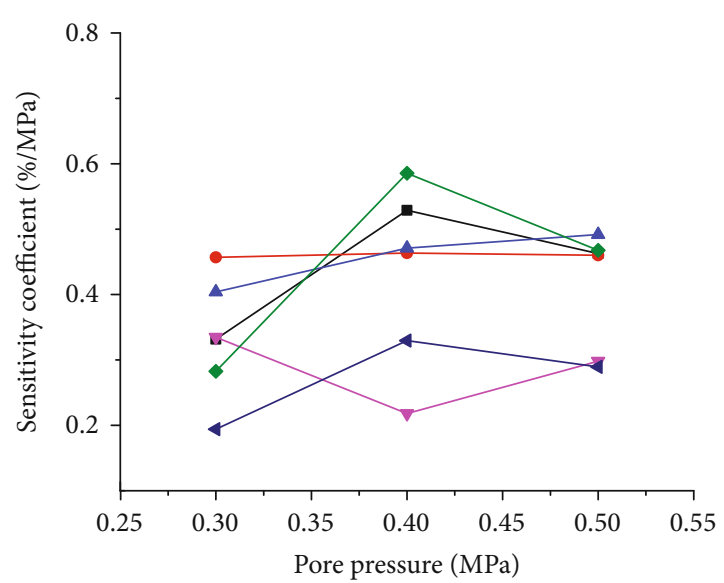

$100^{\circ} \mathrm{C}$ heat-treated Confining pressure
$\rightarrow 5 \mathrm{MPa}$
$\rightarrow 10 \mathrm{MPa}$
$\longrightarrow$
$\longrightarrow 20 \mathrm{MPa}$
$\leftarrow 15 \mathrm{MPa}$
$\longleftarrow 30 \mathrm{MPa}$

(a) $100^{\circ} \mathrm{C}$ heat-treated test piece

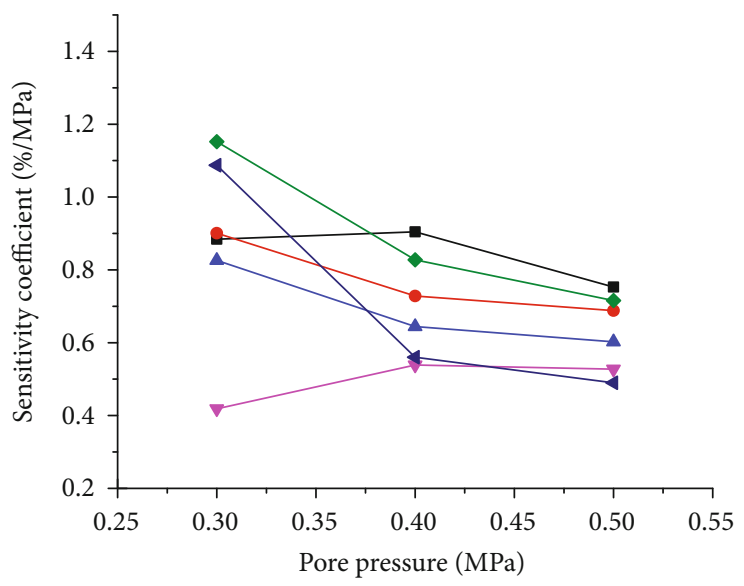

$500^{\circ} \mathrm{C}$ heat-treated

Confining pressure

$\begin{array}{ll}\rightarrow 5 \mathrm{MPa} & \rightarrow 20 \mathrm{MPa} \\ \rightarrow 10 \mathrm{MPa} & \rightarrow 25 \mathrm{MPa} \\ \leftarrow 15 \mathrm{MPa} & \leftarrow 30 \mathrm{MPa}\end{array}$

(c) $500^{\circ} \mathrm{C}$ heat-treated test piece

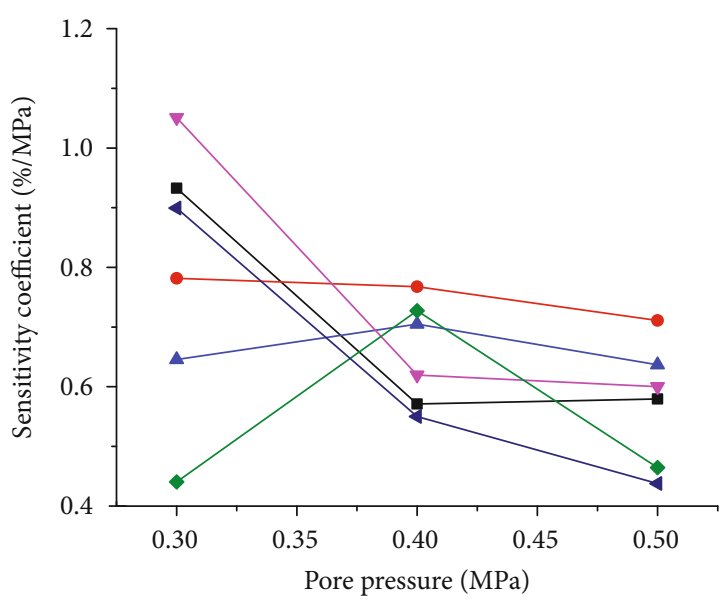

$300^{\circ} \mathrm{C}$ heat-treated

Confining pressure

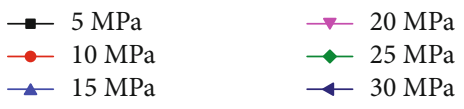

(b) $300^{\circ} \mathrm{C}$ heat-treated test piece

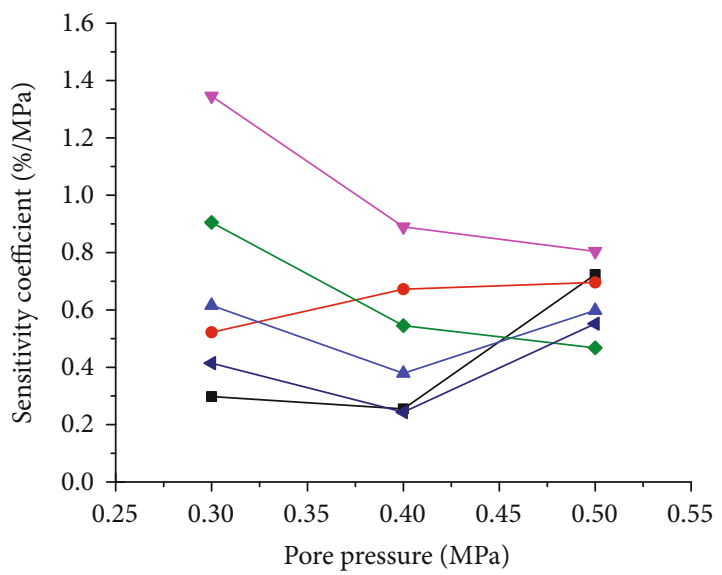

$700^{\circ} \mathrm{C}$ heat-treated

Confining pressure

$$
\begin{array}{ll}
\rightarrow-5 \mathrm{MPa} & \rightarrow 20 \mathrm{MPa} \\
\rightarrow-10 \mathrm{MPa} & \rightarrow-25 \mathrm{MPa} \\
\leftarrow 15 \mathrm{MPa} & \leftarrow 30 \mathrm{MPa}
\end{array}
$$

(d) $700^{\circ} \mathrm{C}$ heat-treated test piece

FIGURE 9: Pore pressure permeability sensitivity coefficient curves.

by comparing the permeability sensitivity coefficients of the confining pressure and pore pressure that the permeability sensitivity coefficients of the pore pressure were an order of magnitude larger than those of the confining pressure. These findings suggested that the influences of the pore pressure on the permeability changes of the specimens were greater than those of the confining pressure under low pore pressure conditions. This conclusion was found to be consistent with that presented by Yang et al. in similar experiments involving mudstone $[10,11]$.

Sandstone and mudstone are both considered to be porous-type rocks. Since porous rocks may have certain similarities, similar experimental results may exist. Therefore, further research will be required to determine whether similar laws exist in fractured-type rock masses.

\section{Analysis of the Circumferential Wave Velocity Anisotropy Law of Rock}

4.1. Analysis of the Wave Velocity Variations of the Rock Samples following the High-Temperature Heat Treatments. According to the study conducted by Lebedev and Kern [22], the free water inside the rock will volatilize below $300^{\circ} \mathrm{C}$ under the influence of high-temperature heat treatments. Then, when the temperature reaches above $500^{\circ} \mathrm{C}$, the crystal water in the rock will volatilize out. These changes 


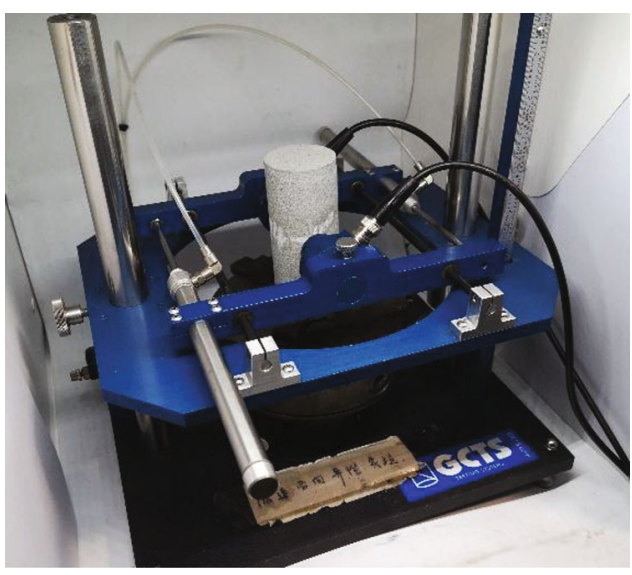

FIgURE 10: Ultrasonic testing system.

will lead to increases in porosity in the rock. Therefore, as the temperature levels continue to rise, the composition of the sandstone (such as quartz) will undergo a phase transition from the $\alpha$ phase to the $\beta$ phase, and the volume will increase, which will lead to thermal cracking in the sandstone. The above-mentioned factors tend to work together to cause the permeability of the rock to change as the heat-treatment temperatures increase $[23,24]$.

When the ultrasonic waves penetrate rock samples, the ultrasonic energy will be weakened when it encounters cracked surfaces or dense pores inside the samples. Therefore, the ultrasonic waves can be used as a method of monitoring the development of the crack structures inside the rock. In this study, the ultrasonic test system of the GCTS test machine was used to perform circumferential wave velocity anisotropy (CVA) on the sandstone samples following heat treatments at different temperature levels (Figure 10). The ultrasonic wave velocity value was tested once for every rotation of $10^{\circ}$. The CVA test results at four heat-treatment temperatures are shown in Figure 11.

It can be seen in Figure 11 that as the heat-treatment temperature increased, the ultrasonic wave velocity had decreased at all angles. This indicated that as the heattreatment temperature increased, the number of pores inside the rock samples had increased and fractures had developed. As a result, the energy and speed of the ultrasonic waves decreased during the process of penetrating the pores and cracks in the specimens.

According to the variation amplitude of the ultrasonic wave velocity at four heat-treatment temperatures, the wave velocity had decreased the most when the temperature level had risen from $500^{\circ} \mathrm{C}$ to $700^{\circ} \mathrm{C}$. The decreases of wave velocity from $100^{\circ} \mathrm{C}$ to $300^{\circ} \mathrm{C}$ were observed to be smaller than those of the former, and the decreases observed from $300^{\circ} \mathrm{C}$ to $500^{\circ} \mathrm{C}$ were the smallest. The analysis results indicated that the free water inside the rock sample continued to volatilize when the temperature rose from $100^{\circ} \mathrm{C}$ to $300^{\circ} \mathrm{C}$. However, when the temperature increased from $300^{\circ} \mathrm{C}$ to $500^{\circ} \mathrm{C}$, the changes inside the rock samples were not obvious and the wave velocity had decreased slightly. When the temperatures increased from $500^{\circ} \mathrm{C}$ to $700^{\circ} \mathrm{C}$, the rock composition of the sandstone samples changed, including the transformation

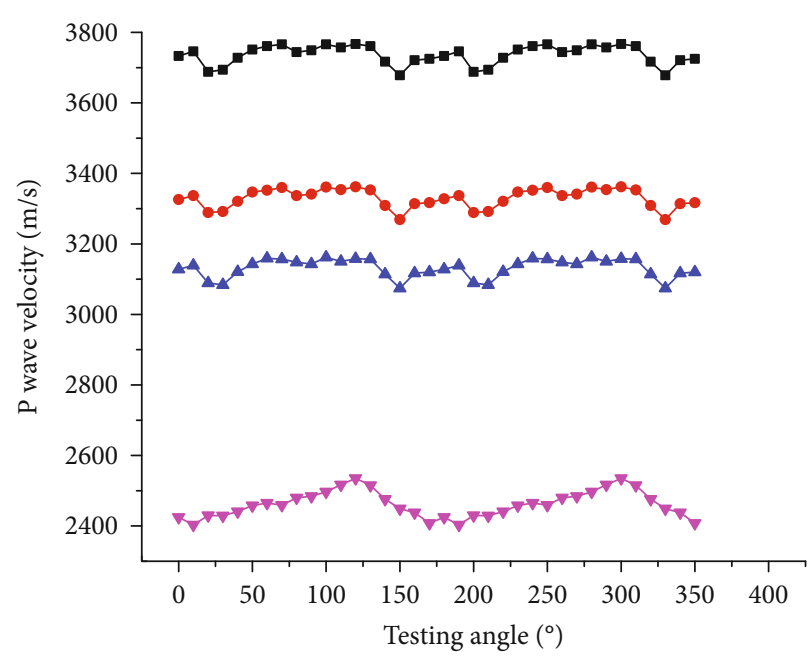

Temperature of

heat treatment

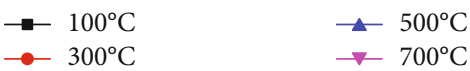

Figure 11: Variation rule of the circumferential wave velocity.

of the quartz and the $(\mathrm{OH})^{-}$ejection from the inner layers of the structures. These factors led to major changes in the pore and fracture structures of the rock, resulting in large decreases in the wave velocity. These phenomena reasonably explained the conclusion that, "permeability increases continuously with increases in heat treatment temperature," as presented in the previous section of this study.

\subsection{Analysis of the Relationship between Circumferential} Wave Velocity Anisotropy and the Ground Stress. In the present study, the rock specimens were under a compressed state due to the original rock stress conditions in the ground. When the rock samples were removed from the ground, they had undergone ground stress release and relaxation deformations. Those expansions produced a large number of unloading microcracks with directional distributions related to the release of the ground stress. The larger the ground stress is, the larger the expansion will be. In other words, the maximum deformations were found along the direction of the maximum principal stress. Therefore, the wave velocity in the direction of maximum principal stress was the minimum [25]. However, some of the rock specimens had undergone low ground stress conditions, and the circumferential wave velocity anisotropy as a result of stress release was not as obvious. In the studies conducted by Fredrich and Wong and Jiang et al., it was determined through various hightemperature heat treatments of granite that the anisotropy of the rock wave velocity became more obvious with the increases in the heat-treatment temperatures, which improved the accuracy of measuring the direction of the ground stress $[23,26]$. In the present study, based on the obtained wave velocity data following the heat treatments at $100^{\circ} \mathrm{C}$ and $700^{\circ} \mathrm{C}$, a radar diagram of the circumferential wave velocity anisotropy test was drawn, as shown in Figure 12.

It can be seen in Figure 12(a) that the maximum principal stress direction of the sandstone sample was approximately 


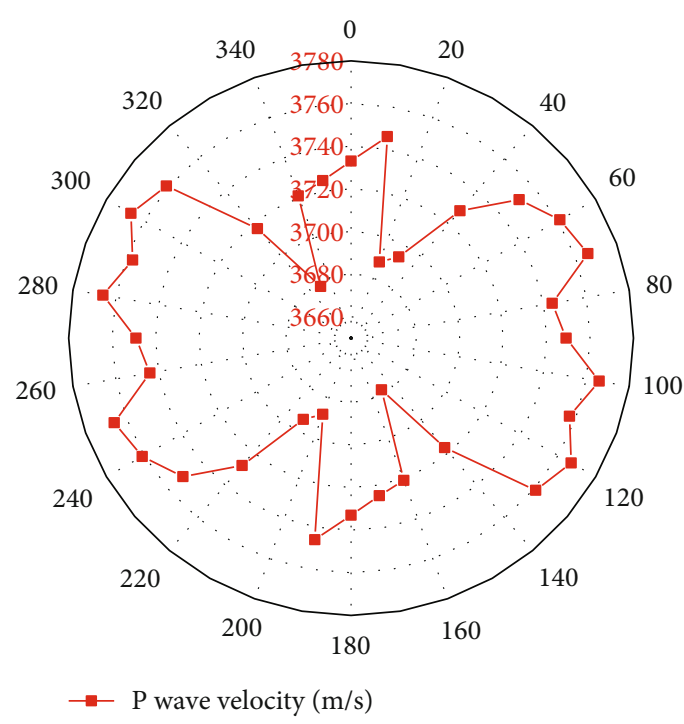

(a) $100^{\circ} \mathrm{C}$ heat-treated test piece

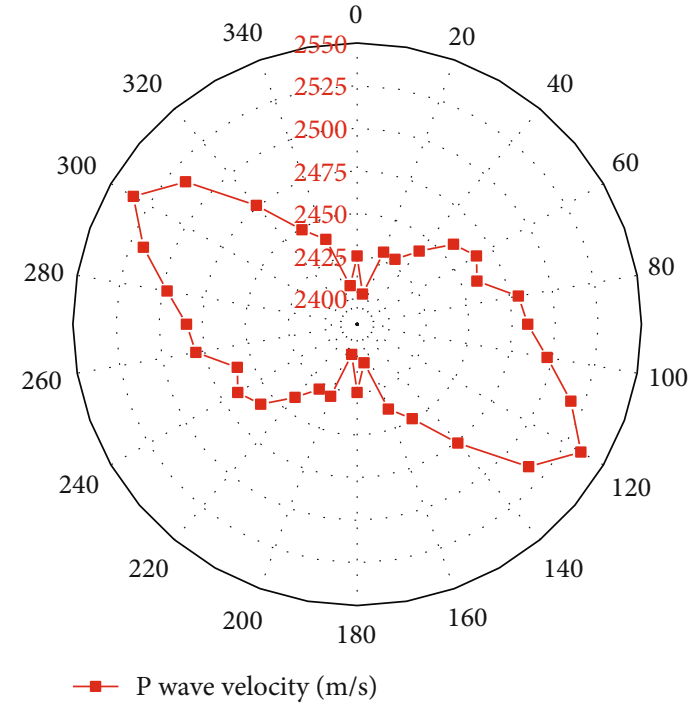

(b) $700^{\circ} \mathrm{C}$ heat-treated test piece

Figure 12: Radar map of the circumferential wave velocity anisotropy.

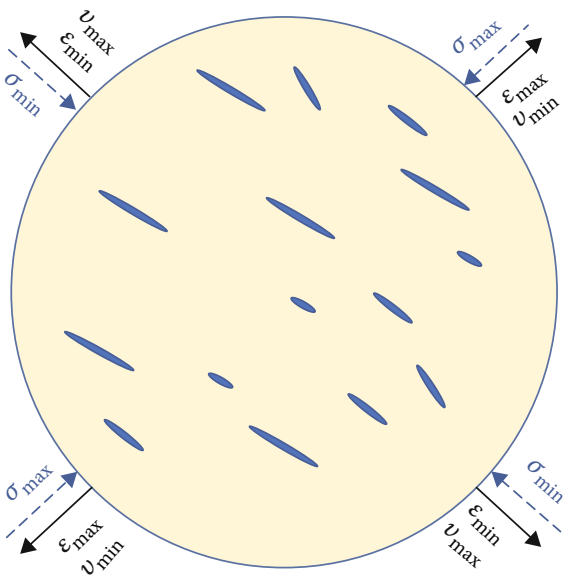

(a) Internal structure of a test piece without heat treatments

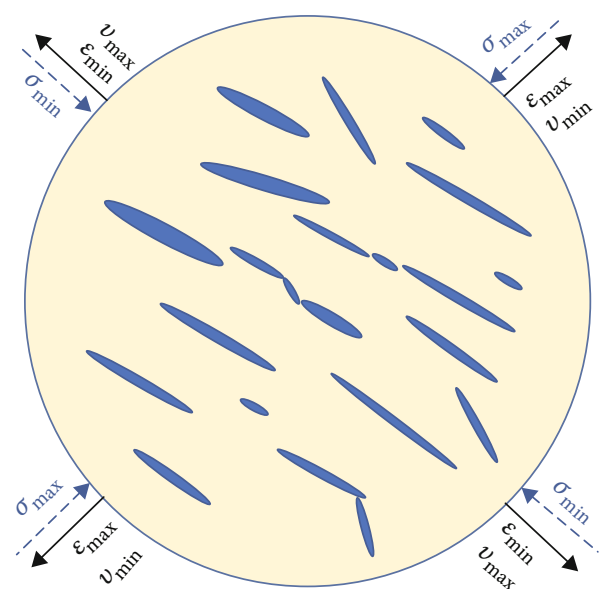

(b) Internal structure of a test piece following high-temperature heat treatments

FiguRE 13: Schematic diagram of unloading cracks generated by the release of ground stress.

$320^{\circ}$ to $40^{\circ}\left(140^{\circ}\right.$ to $\left.220^{\circ}\right)$ within the clockwise rotation angle. As shown in Figure 12(b), following the heat treatment at $700^{\circ} \mathrm{C}$, the maximum principal stress direction was $0^{\circ}$ to $20^{\circ}$ $\left(180^{\circ}\right.$ to $\left.200^{\circ}\right)$ within the clockwise rotation angle. The experimental results showed that the accuracy of wave velocity anisotropy of the sandstone was improved following the high-temperature heat treatments. In addition, as shown in Figure 13(a), due to the release of in situ stress, there were a certain number of microcracks in the processed rock samples. It has been observed that when the ultrasonic waves propagate parallel to the fracture surfaces, the energy attenuation of the ultrasonic waves is small. Meanwhile, when the ultrasonic waves propagate perpendicular to the fracture surfaces, the energy attenuation is large. It was found in this study that following the high-temperature heat treatments, due to such influencing factors as rock dehydration and transformations of the internal components, the microcracks in the rock samples had expanded and extended, forming larger and wider cracks. Then, as the heat-treatment temperatures had increased, the micropores also expanded and penetrated. As shown in Figure 13(b), as a result of the aforementioned changes, the circumferential wave velocity anisotropy of the rock samples became more significant, which was conducive to identifying the direction of the in situ stress.

\section{Analysis of Slippage Effects on Sandstone Permeability under Low Pore Pressure Conditions}

5.1. Causes of Slippage Effects in Gas Seepage Media. A large number of previous tests have revealed that there are significant differences between gas and liquid permeability results. This has been confirmed to be mainly due to the slippage 
effects of gas during its flow in dense rock [23]. Gas molecules collide with other gas molecules during motion, and the distance between two collisions has been defined as a free path. When the pore pressure changes, or the pore radii inside the rock changes, the average free path of the gas molecules will be close to the pore radii. This will lead to the movement of each molecule on the pore walls, resulting in a slip flow rate and changes in the measured permeability, which are referred to as slippage effects. The slippage effects are known to be related to the molecular free paths, average pore radius, and average pore pressure. The molecular free path expression can be written as follows [27]:

$$
\lambda=\frac{\mu}{P_{m}} \sqrt{\frac{\pi R T}{2 M}},
$$

where $\mu$ represents the viscosity coefficient of the gas (Pa.s), $T$ is the ambient temperature of the molecule $\left({ }^{\circ} \mathrm{C}\right), R$ denotes the molar gas constant $(8314 \mathrm{~J} /(\mathrm{K} \cdot \mathrm{mol}))$, $M$ is the molecular weight $(\mathrm{kg} /(\mathrm{K} \cdot \mathrm{mol}))$, and $P_{m}$ indicates the average pore pressure $(\mathrm{Pa})$ of the porous medium.

According to the above equation, the lower the average pore pressure is, the higher the temperature will be, which will result in increases in the average free paths of the molecules. In addition, the more significant the slippage effects are, the larger the measured permeability values will be. For example, when the pore pressure levels increase, the average free paths tend to decrease and the slippage effects are inhibited. As a result, the measured permeability values decrease. The gas pore pressure used in this study's testing process was less than $1 \mathrm{MPa}$, which was considered to be equivalent to a low pore pressure stage. Therefore, it was very likely that slippage effects had caused measured permeability distortions.

5.2. Verification of the Slippage Effects on the Sandstone Specimens. Since the slippage effects will potentially cause the measured permeability to deviate from the absolute permeability, it was necessary to verify the gas test results. Therefore, observations were made in this study in order to determine whether the slippage effects had resulted in the permeability deviations in the examined samples [27].

In the Darcy Law seepage tests, the rock permeability was solved as follows [28]:

$$
k_{g}=\frac{2 Q_{s} \mu L \Delta p_{1}}{A\left(\bar{p}^{2}-p_{0}^{2}\right)},
$$

where $k_{g}$ indicates the gas permeability $\left(\mu \mathrm{m}^{2}\right)$ of the rock sample; $\mu$ is the viscosity coefficient of the seepage gas $(\mathrm{Pa} \cdot \mathrm{s}) ; p_{0}$ represents the atmospheric pressure $(\mathrm{MPa}) ; \bar{p}$ is the average pressure $(\mathrm{MPa}), \bar{p}=p_{1}-\Delta p_{1} / 2 ; A$ denotes the core cross section area $\left(\mu \mathrm{m}^{2}\right)$; and $L$ indicates the core length $(\mathrm{m})$.

It can be seen from the above equation that if the gas seepage follows Darcy's Law, the gas flow rate through a specimen will have a linear relationship with the square deviation of the pressure. However, if the gas flow rate does not have a linear relationship with the square deviation of the pressure, it can be considered that slippage effects have occurred.

In this study's experiments, the gas flow rate was expressed as follows [28]:

$$
Q_{s}=\frac{V_{s} \Delta p_{1}}{\Delta t\left(p_{1}-\Delta p_{1} / 2\right)},
$$

where $Q_{s}$ is the average gas flow rate $\left(\mathrm{m}^{3} / \mathrm{s}\right), V_{s}$ indicates the internal volume of the gas manometer, $p_{1}$ represents the pressure at the inlet end when $t=0$, and $\Delta p_{1}$ is the change in air pressure at the inlet end $(\mathrm{MPa})$ during the time period $t$.

As shown in Figure 14(a), curves were drawn for the relationships between the flow rate and pressure variances under the different confining pressure levels.

Figure 14 shows that under the same confining pressure, with the increases in the square deviations of inlet and outlet pressure levels, the gas flow rates of the sandstone specimens had displayed nonlinear change relationships with the square deviations of the gas pressure. These findings indicated that slippage effects had existed during the sandstone gas seepage process. Previously, Zhu et al. presented a classical linear relation equation to modify the measurements of gas permeability [29]:

$$
k_{g}=k_{\infty}\left(1+\frac{b}{p_{m}}\right) \text {, }
$$

where $k_{g}$ is the gas-measured permeability $\left(\mu \mathrm{m}^{2}\right), k_{\infty}$ represents the absolute permeability, $p_{m}$ is the average inlet and outlet pressure, and $b$ denotes the slip factor. Among these, $b=(4 c / r) \lambda p_{m}$, where $c$ is a constant, $r$ is the hydraulic radius, and $\lambda$ indicates the average free path for a gas molecule.

According to Formulas (5) and (8), the slip ratio is linearly related to the reciprocal of the pore pressure. Therefore, as the pore pressure increases, the gas permeability value will gradually decrease. Figure 15 illustrates a graph showing the observed relationships between the pore pressure and the permeability during the testing process.

As can be seen from Figure 15, following the different heat treatments, the samples had all shown increased pore pressure. Meanwhile, the gas permeability levels had decreased. These results were found to be consistent with the classical linear relation equation given by Klinkenberg. Then, Klinkenberg linear fitting was performed on the permeability and pore pressure curves obtained in this experiment for the purpose of determining [17] the relevant linear fitting data, as shown in Table 3.

5.3. Contribution Rates of the Slippage Effects to the Gas Permeability Levels of the Sandstone Samples. It was found in this study that the confining pressure had changed the pore radii of the specimens, and the pore pressure had changed the mean free paths of the gas seepage. It was believed that both would have some influence on the slippage effects during the seepage experiments, which would subsequently affect the permeability test results. The 


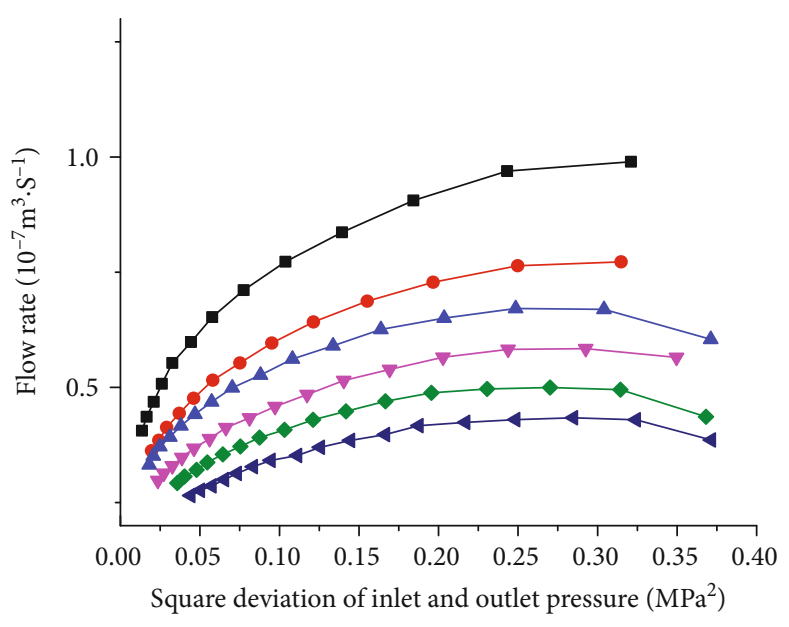

Average pore pressure $0.5 \mathrm{MPa}$

$$
\begin{array}{ll}
\rightarrow 5 \mathrm{MPa} & \rightarrow 20 \mathrm{MPa} \\
\rightarrow 10 \mathrm{MPa} & \longrightarrow 25 \mathrm{MPa} \\
\longleftarrow 15 \mathrm{MPa} & \smile 30 \mathrm{MPa}
\end{array}
$$

(a) $100^{\circ} \mathrm{C}$ heat-treated test piece

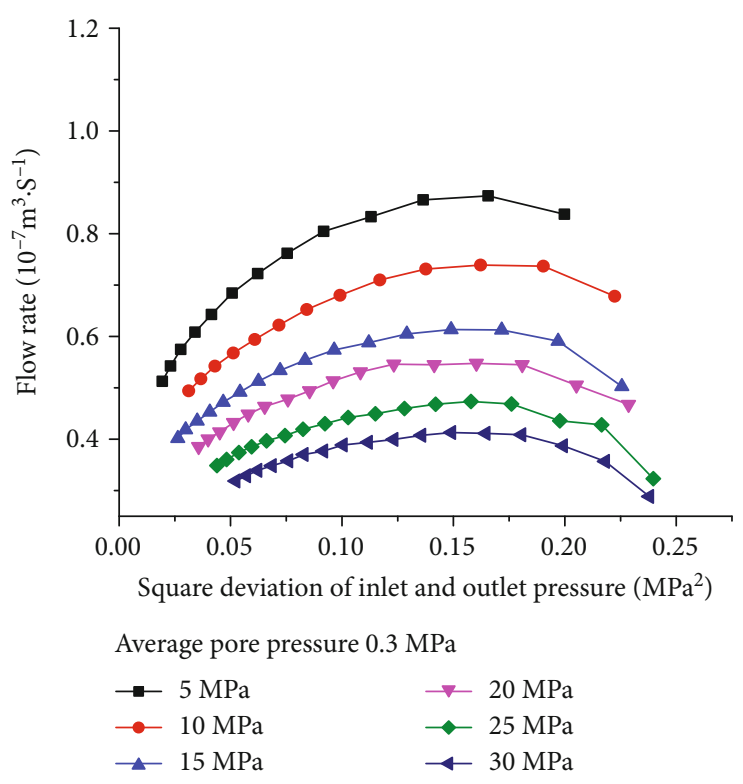

(c) $500^{\circ} \mathrm{C}$ heat-treated test piece

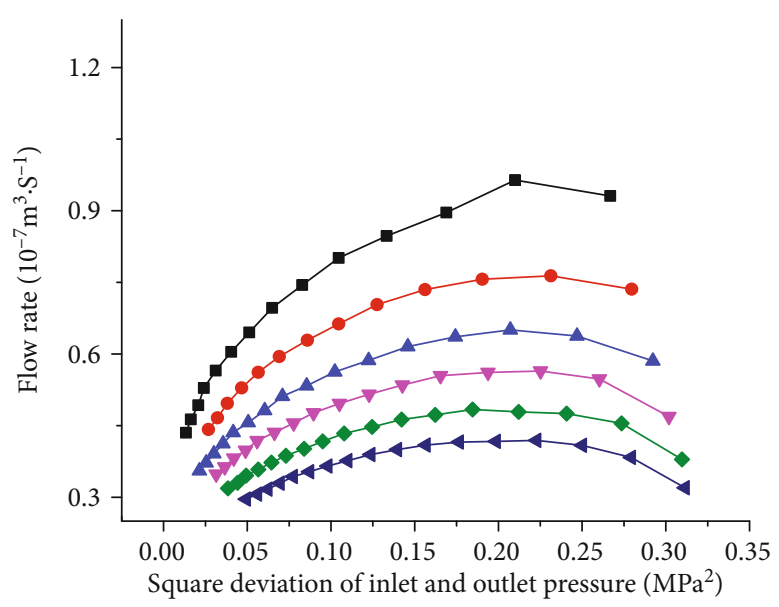

Average pore pressure $0.4 \mathrm{MPa}$

$$
\begin{array}{ll}
\rightarrow-5 \mathrm{MPa} & \rightarrow 20 \mathrm{MPa} \\
\rightarrow 10 \mathrm{MPa} & \rightarrow 25 \mathrm{MPa} \\
\leftarrow 15 \mathrm{MPa} & \multimap 30 \mathrm{MPa}
\end{array}
$$

(b) $300^{\circ} \mathrm{C}$ heat-treated test piece

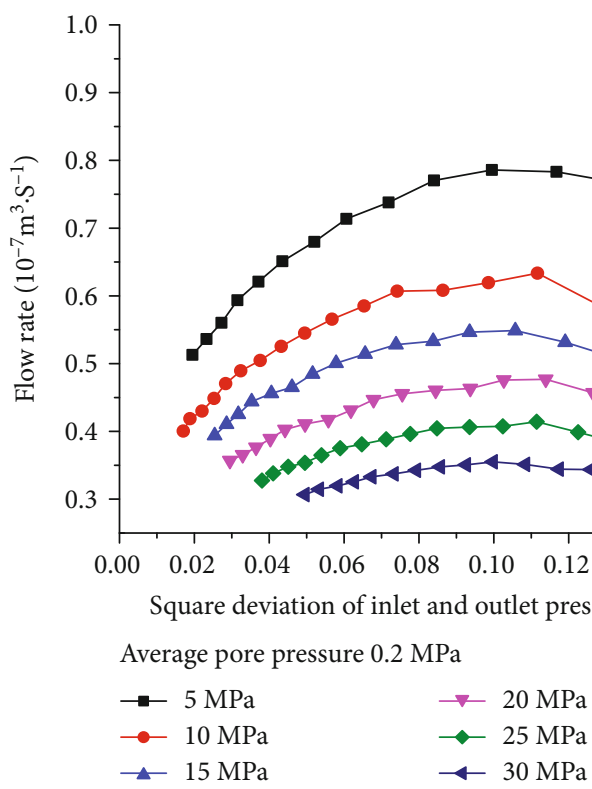

(d) $700^{\circ} \mathrm{C}$ heat-treated test piece

FIgURE 14: Relationships between the square deviations of the inlet and outlet pressure and flow rates.

contribution rate of the slippage effects was expressed by the following formula:

$$
m=\frac{\left|k_{g}-k_{\infty}\right|}{k_{g}} \times 100 \%
$$

Therefore, in accordance with Formula (9), and combined with results detailed in Table 3 , the contribution rates of the slippage effects under the different confining pressures to the gas permeability were ascertained, as shown in Tables 4-7.
It can be seen in Tables $4-7$, under the conditions of a constant confining pressure, as the pore pressure increased, the contribution rates of slippage effects had gradually decreased. These results indicated that the lower the pore pressure, the more obvious the gas slippage effects. The rock samples which had been heat-treated to $100^{\circ} \mathrm{C}$ were observed to have a maximum contribution rate of $67 \%$. The maximum contribution rate of the slipping effect was $57 \%$ at a temperature of $300^{\circ} \mathrm{C}$. The maximum contribution rate of the slipping effect was $57 \%$ at a temperature of $500^{\circ} \mathrm{C}$. The maximum contribution rate of the slipping effect was $33 \%$ at a temperature of $700^{\circ} \mathrm{C}$. The average contribution rates of the four heat-treatment temperatures were determined to be 


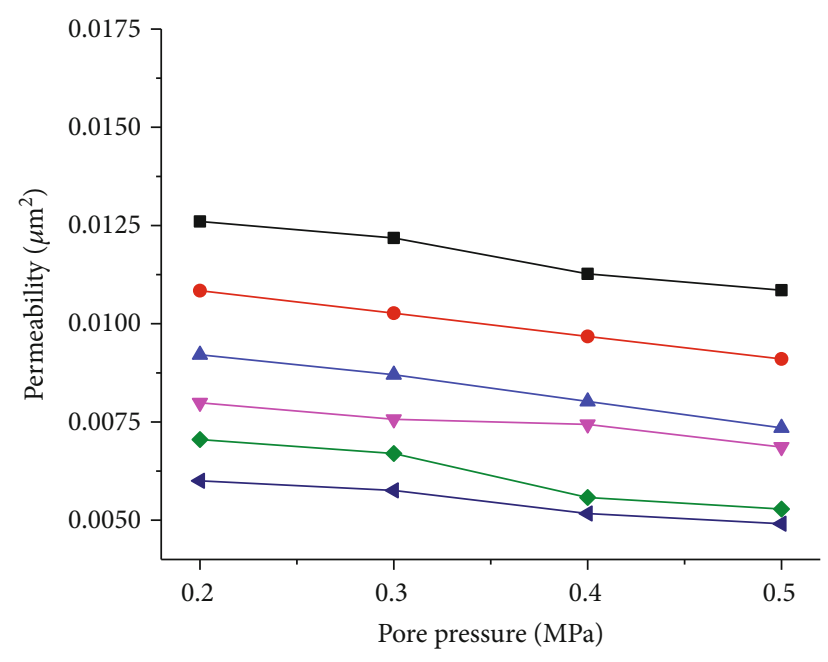

$100^{\circ} \mathrm{C}$ heat-treated confining pressure

$\begin{array}{ll}\rightarrow 5 \mathrm{MPa} & \rightarrow 20 \mathrm{MPa} \\ \rightarrow 10 \mathrm{MPa} & \rightarrow 25 \mathrm{MPa} \\ \leftarrow 15 \mathrm{MPa} & \multimap 30 \mathrm{MPa}\end{array}$

(a) $100^{\circ} \mathrm{C}$ heat-treated test piece

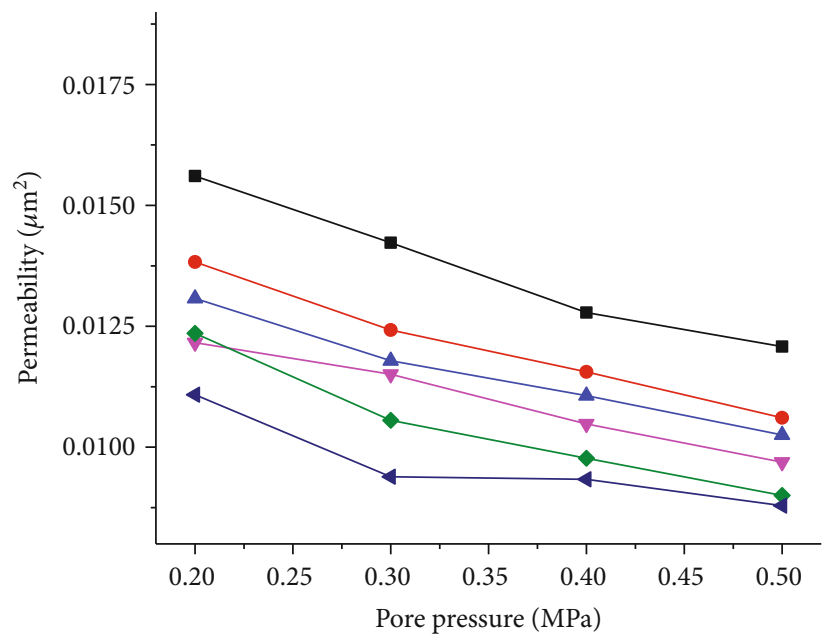

$500^{\circ} \mathrm{C}$ heat-treated confining pressure

$$
\begin{array}{ll}
\rightarrow 5 \mathrm{MPa} & \rightarrow 20 \mathrm{MPa} \\
\rightarrow-10 \mathrm{MPa} & \multimap-25 \mathrm{MPa} \\
\leftarrow 15 \mathrm{MPa} & \longleftarrow 30 \mathrm{MPa}
\end{array}
$$

(c) $500^{\circ} \mathrm{C}$ heat-treated test piece

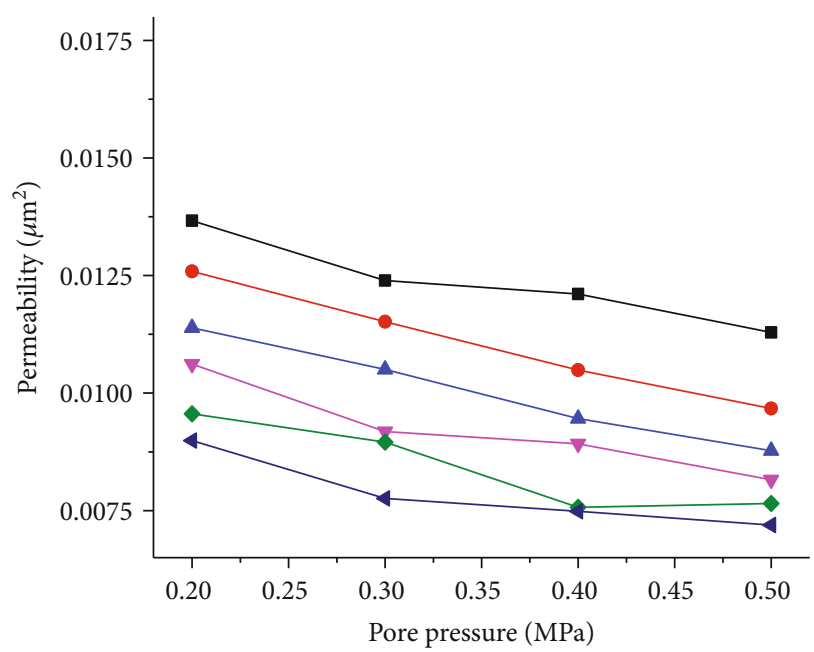

$300^{\circ} \mathrm{C}$ heat-treated confining pressure

$$
\begin{array}{ll}
\rightarrow 5 \mathrm{MPa} & \rightarrow 20 \mathrm{MPa} \\
\rightarrow-10 \mathrm{MPa} & \rightarrow-25 \mathrm{MPa} \\
\leftarrow 15 \mathrm{MPa} & \multimap 30 \mathrm{MPa}
\end{array}
$$

(b) $300^{\circ} \mathrm{C}$ heat-treated test piece

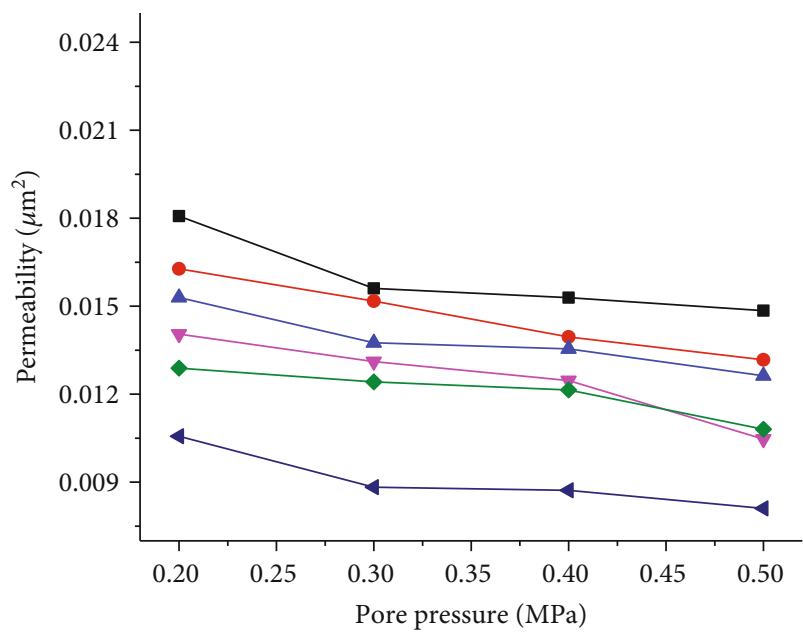

$700^{\circ} \mathrm{C}$ heat-treated confining pressure

$$
\begin{array}{ll}
\leftarrow 5 \mathrm{MPa} & \rightarrow 20 \mathrm{MPa} \\
\rightarrow 10 \mathrm{MPa} & \rightarrow-25 \mathrm{MPa} \\
\leftarrow 15 \mathrm{MPa} & \multimap 30 \mathrm{MPa}
\end{array}
$$

(d) $700^{\circ} \mathrm{C}$ heat-treated test piece

FIGURE 15: The pore pressure and permeability curves.

$36.47 \%\left(100^{\circ} \mathrm{C}\right), \quad 33.88 \%\left(300^{\circ} \mathrm{C}\right), \quad 35.66 \%\left(500^{\circ} \mathrm{C}\right)$, and $15.64 \%\left(700^{\circ} \mathrm{C}\right)$. Therefore, the contribution rates of slippage effects were observed to decrease with the increases in the heat-treatment temperatures. It was observed that following the high-temperature heat treatments, the free water and crystal water were volatilized inside the rock samples, which resulted in pore radii changes. Furthermore, the internal compositions of the rock samples had changed, causing thermal cracking. The above-mentioned factors had resulted in changes in the ratios of the free paths of the gas molecules to the pore radii, and the contribution rates of the slippage effects decreased with the increases in the heat-treatment temperatures.

In the present study, the contribution rates of the slippage effects did not change significantly with the increases in the confining pressure. These results indicated that the pores and cracks in the sandstone specimens were relatively complex. During the process of increasing confining pressure, the specimens had also undergone complex processes of crack closures or crack openings. 
TABLE 3: Slippage factor fitting results.

\begin{tabular}{|c|c|c|c|c|c|}
\hline Fitting result & Temperature $\left({ }^{\circ} \mathrm{C}\right)$ & Confining pressure $(\mathrm{MPa})$ & Absolute permeability $\left(\mu \mathrm{m}^{2}\right)$ & Slip factor: $b$ & $R$ value \\
\hline$k_{g}=9.86773 *\left(1+0.05872 / p_{m}\right)$ & 100 & 5 & $9.86773 \times 10^{-3}$ & 0.05872 & 0.89064 \\
\hline$k_{g}=8.20541 *\left(1+0.06712 / p_{m}\right)$ & 100 & 10 & $8.20541 \times 10^{-3}$ & 0.06712 & 0.8984 \\
\hline$k_{g}=6.45132 *\left(1+0.12175 / p_{m}\right)$ & 100 & 15 & $6.45132 \times 10^{-3}$ & 0.09036 & 0.84558 \\
\hline$k_{g}=6.41437 *\left(1+0.05104 / p_{m}\right)$ & 100 & 20 & $6.41437 \times 10^{-3}$ & 0.05104 & 0.78447 \\
\hline$k_{g}=4.21344 *\left(1+0.1435 / p_{m}\right)$ & 100 & 25 & $4.21344 \times 10^{-3}$ & 0.1435 & 0.79904 \\
\hline$k_{g}=4.29634 *\left(1+0.08435 / p_{m}\right)$ & 100 & 30 & $4.29634 \times 10^{-3}$ & 0.08435 & 0.82638 \\
\hline$k_{g}=10.00299 *\left(1+0.07357 / p_{m}\right)$ & 300 & 5 & $10.00299 \times 10^{-3}$ & 0.07357 & 0.94475 \\
\hline$k_{g}=8.05097 *\left(1+0.11674 / p_{m}\right)$ & 300 & 10 & $8.05097 \times 10^{-3}$ & 0.11674 & 0.93318 \\
\hline$k_{g}=7.30418 *\left(1+0.11637 / p_{m}\right)$ & 300 & 15 & $7.30418 \times 10^{-3}$ & 0.11637 & 0.91836 \\
\hline$k_{g}=6.74855 *\left(1+0.11408 / p_{m}\right)$ & 300 & 20 & $6.74855 \times 10^{-3}$ & 0.11408 & 0.95355 \\
\hline$k_{g}=6.1865 *\left(1+0.11408 / p_{m}\right)$ & 300 & 25 & $6.1865 \times 10^{-3}$ & 0.11325 & 0.88078 \\
\hline$k_{g}=5.95165 *\left(1+0.09976 / p_{m}\right)$ & 300 & 30 & $5.95165 \times 10^{-3}$ & 0.09976 & 0.96832 \\
\hline$k_{g}=9.91036 *\left(1+0.11841 / p_{m}\right)$ & 500 & 5 & $9.91036 \times 10^{-3}$ & 0.11841 & 0.95365 \\
\hline$k_{g}=8.81055 *\left(1+0.11655 / p_{m}\right)$ & 500 & 10 & $8.81055 \times 10^{-3}$ & 0.11655 & 0.96073 \\
\hline$k_{g}=8.65558 *\left(1+0.10407 / p_{m}\right)$ & 500 & 15 & $8.65558 \times 10^{-3}$ & 0.10407 & 0.96894 \\
\hline$k_{g}=8.42846 *\left(1+0.09362 / p_{m}\right)$ & 500 & 20 & $8.42846 \times 10^{-3}$ & 0.09362 & 0.8525 \\
\hline$k_{g}=6.92297 *\left(1+0.15748 / p_{m}\right)$ & 500 & 25 & $6.92297 \times 10^{-3}$ & 0.15748 & 0.99382 \\
\hline$k_{g}=7.30189 *\left(1+0.10025 / p_{m}\right)$ & 500 & 30 & $7.30189 \times 10^{-3}$ & 0.10025 & 0.90743 \\
\hline$k_{g}=12.51976 *\left(1+0.08558 / p_{m}\right)$ & 700 & 5 & $12.51976 \times 10^{-3}$ & 0.08558 & 0.92428 \\
\hline$k_{g}=11.39367 *\left(1+0.08891 / p_{m}\right)$ & 700 & 10 & $11.39367 \times 10^{-3}$ & 0.08891 & 0.93135 \\
\hline$k_{g}=11.16607 *\left(1+0.0737 / p_{m}\right)$ & 700 & 15 & $11.16607 \times 10^{-3}$ & 0.0737 & 0.93469 \\
\hline$k_{g}=9.22503 *\left(1+0.11147 / p_{m}\right)$ & 700 & 20 & $9.22503 \times 10^{-3}$ & 0.11147 & 0.89139 \\
\hline$k_{g}=10.21858 *\left(1+0.0563 / p_{m}\right)$ & 700 & 25 & $10.21858 \times 10^{-3}$ & 0.0563 & 0.87189 \\
\hline$k_{g}=6.54563 *\left(1+0.11957 / p_{m}\right)$ & 700 & 30 & $6.54563 \times 10^{-3}$ & 0.11957 & 0.92611 \\
\hline
\end{tabular}

TABLE 4: Contribution rates of the gas slippage effects $\left(100^{\circ} \mathrm{C}\right)$.

\begin{tabular}{lcccccc}
\hline \multirow{2}{*}{ Pore pressure (MPa) } & 5 & 10 & \multicolumn{2}{c}{ Confining pressure (MPa) } & 20 & 30 \\
\hline 0.2 & 0.277069 & 0.321477 & 0.427681 & 0.245527 & 0.673934 \\
0.3 & 0.234694 & 0.251305 & 0.348748 & 0.179777 & 0.589421 \\
0.4 & 0.141999 & 0.17909 & 0.243681 & 0.159861 & 0.323769 & 0.3396865 \\
0.5 & 0.099783 & 0.109525 & 0.139466 & 0.06983 & 0.254414 & 0.142215 \\
\hline
\end{tabular}

TABLE 5: Contribution rates of the gas slippage effects $\left(300^{\circ} \mathrm{C}\right)$.

\begin{tabular}{lcccccc}
\hline \multirow{2}{*}{ Pore pressure (MPa) } & 5 & 10 & \multicolumn{2}{c}{ Confining pressure (MPa) } & 25 & 25 \\
\hline 0.2 & 0.366277 & 0.563398 & 0.558867 & 0.573132 & 0.544965 \\
0.3 & 0.238843 & 0.43071 & 0.438063 & 0.36032 & 0.447634 & 0.510242 \\
0.4 & 0.21023 & 0.302757 & 0.295092 & 0.322143 & 0.223602 & 0.257637 \\
0.5 & 0.128744 & 0.201287 & 0.201405 & 0.208477 & 0.237109 & 0.208675 \\
\hline
\end{tabular}


TABLE 6: Contribution rates of the gas slippage effects $\left(500^{\circ} \mathrm{C}\right)$.

\begin{tabular}{lcccccc}
\hline \multirow{2}{*}{ Pore pressure (MPa) } & 5 & 10 & Confining pressure (MPa) & 25 & 30 \\
\hline 0.2 & 0.574869 & 0.569753 & 0.510744 & 0.442865 & 0.484533 & 0.518131 \\
0.3 & 0.435611 & 0.410177 & 0.361753 & 0.365337 & 0.524797 & 0.285722 \\
0.4 & 0.290015 & 0.311748 & 0.278328 & 0.243383 & 0.411327 & 0.278633 \\
0.5 & 0.219101 & 0.204108 & 0.184779 & 0.149865 & 0.300355 & 0.20409 \\
\hline
\end{tabular}

TABLE 7: Contribution rates of the gas slippage effects $\left(700^{\circ} \mathrm{C}\right)$.

\begin{tabular}{lcccccc}
\hline \multirow{2}{*}{ Pore pressure (MPa) } & 5 & 10 & \multicolumn{2}{c}{ Confining pressure (MPa) } & 20 & 25 \\
\hline 0.2 & 0.204133 & 0.165205 & 0.101151 & 0.021287 & 0.081477 \\
0.3 & 0.007128 & 0.068362 & 0.305465 & 0.154198 & 0.010509 & 0.349152 \\
0.4 & 0.018074 & 0.038854 & 0.324365 & 0.071718 & 0.073614 & 0.332584 \\
0.5 & 0.053392 & 0.106899 & 0.137565 & 0.008503 & 0.26915 & 0.238551 \\
\hline
\end{tabular}

The previous relevant studies have shown that in practical projects, when the contribution rates of the gas slippage effects are higher than $5 \%$, the slippage effects caused by gas seepage should be considered and cannot be ignored [18]. The specimens examined in this experiment were taken from the Ehebaolige underground gasification coalfield in Inner Mongolia. The calculation results showed that the slippage contribution rates were above $5 \%$ in most of the measurement points. During underground coal gasification processes, the gasifier and the gas generated by combustion will generate air pressure. The effective gas also has a certain pressure in the internal flow process of fractured rock. Therefore, the effect of slippage on gas flow in actual projects should always be considered.

\section{Conclusions}

In the present study, the permeability variations of sandstone specimens under different confining pressures and pore pressures following high-temperature heat treatments were examined. Then, combined with the theory of slippage effects, the change rule of rock permeability under low pore pressure was analyzed, and the main conclusions were as follows:

(1) During the process of the heat-treatment temperatures rising from $100^{\circ} \mathrm{C}$ to $700^{\circ} \mathrm{C}$, the water volatilization and structural changes in the rock samples had led to increases in the permeability levels. Therefore, in accordance with the corresponding relationships between the pore pressure and permeability, macroporous sandstone with an order of permeability of $10^{-3} \mu \mathrm{m}^{2}$ will also experience the phenomenon in which the measured permeability results will deviate from the absolute permeability. It was concluded that the rock samples with the order of $10^{-3}-10^{-6} \mu \mathrm{m}^{2}$ permeability may experience slippage effects
(2) The permeability was found to present a downward trend with increases in the confining pressure and pore pressure levels. It was determined that according to the analysis results of the sensitivity coefficients, at the low pore pressure stage (less than $1 \mathrm{MPa}$ ), the influences of the pore pressure on the permeability changes were greater than those of the confining pressure

(3) In the present study, Klinkenberg's first linear fitting equation was used to modify the gas permeability test results which had deviated from the real values. The absolute permeability values of the samples were obtained through the aforementioned fitting equation. The fitting equation confirmed that the occurrences of slippage effects were closely related to the pore pressure levels. It was also found that the permeability contribution rates of the sandstone samples were generally higher than $5 \%$. Therefore, it was necessary to modify the permeability deviations caused by slippage effects in order to better apply the experimental results in practice

(4) According to the ultrasonic wave velocity test results, when the heat-treatment temperature rose to more than $500^{\circ} \mathrm{C}$, the internal compositions of the sandstone samples had changed, leading to increases in the number of pores and crack expansions. Subsequently, this resulted in a maximum decrease in the wave velocity. This study's high-temperature heat treatments of sandstone specimens had effectively improved the measurement accuracy of the circumferential wave velocity anisotropy method currently used for determining the directions of ground stress

\section{Data Availability}

The data used to support the findings of this study are included within the article. 


\section{Conflicts of Interest}

The authors declare that they have no conflicts of interest.

\section{Acknowledgments}

The authors would like to thank the Beijing Outstanding Young Scientist Program (BJJWZYJH01201911413037) and the Shaanxi Coal Group Key Project (2018SMHKJ-A-J-03) and are thankful for the projects (Grant Nos: 51622404 and 41877257) supported by NSFC of China.

\section{References}

[1] R. Yanxia, Y. E. Bin, and C. Zirui, "Research progress of gas slippage in compact porous medium," Journal of Geomechanics, vol. 24, no. 4, pp. 63-69, 2018.

[2] R. M. Weinbrandt, H. J. Ramey Jr., and F. J. Casse, "The effect of temperature on relative and absolute permeability of sandstones," Society of Petroleum Engineers Journal, vol. 15, no. 5, pp. 376-384, 1975.

[3] F. J. Casse and H. J. Ramey Jr., "The effect of temperature and confining pressure on single-phase flow in consolidated rocks (includes associated paper 9087)," Journal of Petroleum Technology, vol. 31, no. 8, pp. 1051-1059, 1979.

[4] J. Zuo, H. Xie, and H. Zhou, "Experimental research on thermal cracking of sandstone under different temperature," Chinese Journal of Geophysics, vol. 50, no. 4, pp. 204-209, 2007.

[5] J. Zuo, H. Zhou, Y. Fang, B. Meng, and R. Peng, "Experiment research on thermal cracking of deep granite in Beishan region, Gansu province," Chinese Journal of Rock Mechanics \& Engineering, vol. 30, no. 6, pp. 1107-1115, 2011.

[6] W. Lin, "Permanent strain of thermal expansion and thermally induced microcracking in Inada granite," Journal of Geophysical Research Solid Earth, vol. 107, no. B10, pp. ECV 3-1-ECV 3-16, 2002.

[7] I. Ali and N. A. Malik, "A realistic transport model with pressure-dependent parameters for gas flow in tight porous media with application to determining shale rock properties," Transport in Porous Media, vol. 124, no. 3, pp. 723-742, 2018.

[8] Y. Yang and A. C. Aplin, "Permeability and petrophysical properties of 30 natural mudstones," Journal of Geophysical Research, vol. 112, no. B3, article B03206, 2007.

[9] Y. Yang and A. C. Aplin, "A permeability-porosity relationship for mudstones," Marine and Petroleum Geology, vol. 27, no. 8, pp. 1692-1697, 2010.

[10] Y. Yang, W. Zhang, Y. Gao et al., "Influence of stress sensitivity on microscopic pore structure and fluid flow in porous media," Journal of Natural Gas Science and Engineering, vol. 36, pp. 20-31, 2016.

[11] Y. Yang, Z. Liu, Z. Sun et al., "Research on stress sensitivity of fractured carbonate reservoirs based on CT technology," Energies, vol. 10, no. 11, p. 1833, 2017.

[12] H. Chen, Y. Qin, G. Li et al., "Study on stress sensitivity of coal rock permeability based on pulse-decay method," Coal Science and Technology, vol. 46, no. 6, pp. 167-172, 2018.

[13] D. Chen, Z. Pan, and Z. Ye, "Dependence of gas shale fracture permeability on effective stress and reservoir pressure: Model match and insights," Fuel, vol. 139, pp. 383-392, 2015.
[14] Z. Hong-xue, L. I. U. Wei-qun, and Z. H. U. Li, "Fracture permeability model and experiments of shale gas reservoirs," Rock and Soil Mechanics, vol. 36, no. 3, pp. 719-729, 2015.

[15] L. J. Klinkenberg, "The permeability of porous media to liquids and gases," API Drilling and Production Practice, vol. 23, pp. 200-213, 1941.

[16] M. Fourar, G. Radilla, R. Lenormand, and C. Moyne, "On the non-linear behavior of a laminar single-phase flow through two and three-dimensional porous media," Advances in Water Resources, vol. 27, no. 6, pp. 669-677, 2004.

[17] G. H. Tang, W. Q. Tao, and Y. L. He, "Gas slippage effect on microscale porous flow using the lattice Boltzmann method," Physical Review E, vol. 72, no. 5, article 056301, 2005.

[18] G. Y. Zhu, X. G. Liu, L. Shu-tie, H. Yan-Zhang, and H. MingQiang, "A study of slippage effect of gas percolation in low permeability gas pools," Natural Gas Industry, vol. 27, no. 5, pp. 44-47, 2007.

[19] J. Ma, J. P. Sanchez, K. Wu, G. D. Couples, and Z. Jiang, “A pore network model for simulating non-ideal gas flow in micro- and nano- porous materials," Fuel, vol. 116, no. 1, pp. $498-508,2014$.

[20] B. A. Suleimanov, A. A. Suleymanov, E. M. Abbasov, and E. T. Baspayev, "A mechanism for generating the gas slippage effect near the dewpoint pressure in a porous media gas condensate flow," Journal of Natural Gas Science and Engineering, vol. 53, pp. 237-248, 2018.

[21] S. Xie, C. Jiao, S. He et al., "An experimental study on stressdependent sensitivity of ultra-low permeability sandstone reservoirs," Acta Petrolei Sinica, vol. 32, no. 3, pp. 489-494, 2011.

[22] E. B. Lebedev and H. Kern, "The effect of hydration and dehydration reactions on wave velocities in basalts," Tectonophysics, vol. 308, no. 3, pp. 331-340, 1999.

[23] J. T. Fredrich and T. F. Wong, "Micromechanics of thermally induced cracking in three crustal rocks," Journal of Geophysical Research Solid Earth, vol. 91, no. B12, pp. 12743-12764, 1986.

[24] Z. Yuan, Z. Yangsheng, and G. Wu, "Meso-structure and pattern of thermal cracking of Luhui granite," Journal of Lanzhou Uinversity of Technology, vol. 36, no. 6, pp. 115-118, 2010.

[25] B. Amadei, W. Z. Savage, and H. S. Swolfs, "Gravitational stresses in anisotropic rock masses," International Journal of Rock Mechanics and Mining Sciences \& Geomechanics Abstracts, vol. 24, no. 1, pp. 5-14, 1987.

[26] G. Jiang, J. P. Zuo, L. Y. Li, T. Ma, and X. Wei, “The evolution of cracks in Maluanshan granite subjected to different temperature processing," Rock Mechanics and Rock Engineering, vol. 51, no. 6, pp. 1683-1695, 2018.

[27] C. Jia, H. Wang, W. Xu, J. Zuo, and F. Skoczylas, "Study on gas permeation and slippage effects in rock mass of underground water-sealed cave," Engineering Mechanics, vol. 32, no. 8, pp. 50-57, 2015.

[28] H. L. Wang, W. Y. Xu, M. Cai, and J. Zuo, "An experimental study on the slippage effect of gas flow in a compact rock," Transport in Porous Media, vol. 112, no. 1, pp. 117-137, 2016.

[29] G. Y. Zhu, L. Liu, Z. M. Yang, X. G. Liu, Y. G. Guo, and Y. T. Cui, "Experiment and mathematical model of gas flow in low permeability porous media," New Trends in Fluid Mechanics Research, pp. 534-537, 2007. 